\title{
Die Prämonstratenserabtei Steinfeld im 13. Jahrhundert.
}

\author{
Von \\ Theodor Paas.
}

Einleitung.

Nachdem der Kölner Erzbischof Friedrich I. im Jahre 1121 in das Augustiner-Cborherrenstift Steinfeld die Söhne des hl. Norbert eingeführt hatte, nahm der Vorsteher Evervin den Titel Propst an, durch welchen die Abstammung der Prämonstratenser von den Augustinern zum Ausdruck kam. Im Laufe der Zeit alher machte sich im Prämonstratenserorden das Streben geltend, den Titel Propst mit dem Titel Abt zu vertauschen, weil die letztere Bezeichnung als vornehmer galt und ihre allgemeine Annahme seitens der Vorsteher der einzelnen Klöster eine gewisse Einheitlichkeit in die Ordensverfassung brachte. Selbst die päpstliche Kurie war bereit, die Prämonstratenser in diesem Streben zu unterstützen. Denn der Papst Eugen III. machte im Jahre 1145 den Erzbischöfen und Bischöfen die Mitteilung, dass die Prämonstratenser auf ibrem Generalkapitel in Prémontré den Beschluss gefasst hätten, an die Stelle der bisherigen Pröpste in Zukunft İbte zu berufen; da dieser Beschluss nicht aus Stolz oder Überhebung, sondern zum Zwecke einer besseren Ordenszucht gefasst sei, befehle er ibnen, die von den Klöstern erwählten Vorsteher zil Äbten zu benedizieren, sofern sie von dem Generalabt in Prémontré darum angegangen würden ${ }^{1}$ ).

1) S. J. Le Paige, Bibliotheca Praemonstratensis ordinis. Parisiis 1633, p. 626. G. Schreiber, Kurie und Kloster im 12. Jahrhundert. 1. Bd. Stuttgart 1910, S. 162 ; 2. Bd. Stuttgart 1910, S. 324 f. 331 . Vgl. Annalen des Historischen Vereins für den Niederrhein, insbesondere die alte Erzdiözese Köln, 93. Heft. Köln 1912, S. 25 (fortan zitiert: Annalen). 
Da viele Prämonstratenserklöster, mit welchen das Stein. felder Stift in Beziehung stand, um die Mitte des 12. Jahrhunderts diese Neuerung bereits eingeführt hatten, z. B. Arnstein a. d. Lahn'1), Justus mons in der Diözese Metz ${ }^{2}$ ), Rommersdorf bei Neuwied ${ }^{3}$ ), Strahow und Selau in Böhmen ${ }^{4}$ ), erschien es für das Kloster Steinfeld im eigenen Interesse geboten, sich ibr ebenfalls anzuschliessen, zumal es in Hinsicht auf seine weitreichende, achtunggebietende Stellung sich jenen Klöstern mindestens ebenbürtig an die Seite stellen konnte. Nach dem Tode des fünften Propstes (Hermann) im Jahre 1184 trat die Neuerung in Steinfeld in Kraft; aus der Prämonstratenserpropstei wurde eine Prämonstratenserabtei.

\section{Die Altei Steinfeld um die Wende des 12. Jahrhunderts. Die Äbte Albert, Erenfried und Eberhard (1184--1211).}

1. Abt Albert (1184-1189).

Als die Chorherren der Abtei Rommersdorf im Jabre 1179 zur Wahl eines neuen Abtes schritten, richteten sie ihr Augenmerk auf den Kanonikus Albert im Kloster Steinfeld, einen Mann von erprobtem Lebenswandel. Dieser war jedoch nicht zu bewegen, das ihm zugedachte Amt anzunehmen, und blieb darum in seiner bisherigen Stellung ${ }^{5}$ ). Aber im Jahre 1184, als in Steinfeld das Amt des Vorstehers neu zu besetzen war, vereinigten seine eigenen

1) S. F. W. E. Roth, Eine Briefsammlung des Propstes Ulrich von Steinfeld aus dem 12. Jahrhundert (= Zeitschrift des Aachener Geschichtsvereins, herausgegeben von E. Fromm, 18 Bd. Aachen 1896, S. 257. 304). Wahrscheinlich war das Stift Arnstein im Jahre 1139 von vornherein schon als Abtei gegründet worden. Die Gründungsurkunde ist zwar nicht erhalten, aber die Bestätigungsurkunde des Papstes Innocenz II. vom Jahre 1142 ist an den A b t Gottfried gerichtet. S. Becker, Das Nekrologium der vormaligen Prämonstratenserabtei Arnstein a. d. Lahn. Wiesbaden 1881, S. 220 f. H. Beyer, Urkundenbuch zur Geschichte der jetzt die preussischen Regierungsbezirke Koblenz und Trier bildenden mittelrheinischen Territorien. 1. Bd. Koblenz 1860, S. 581 Nr. 525 (fortan zitiert: Mittelrheinisches Urkundenbuch).

2) S. Zeitschr. des Aachener Geschichtsvereins 18, S. 262, 276.

3) S. ebenda S. 307.

4) S. ebenda S. 263. 265. 271. 281. 283. 293, 297, 305. 309.

5) S. Ch. de Stramberg, Metropolis ecclesiae Trevericae. Tomus II. Confluentibus 1856 , p. 18 sq. 
Die Prïmonstratenserabtei Steinfeld im 13. Jahrhundert.

Mitbrider ihre Stimmen auf ihn und wählten ihn zu ihrem geistlichen Oberhaupte ${ }^{1}$ ).

Die älteste erhaltene Urkunde, in welcher er als Abt auftritt, ist rom 15. Dezember 1185 datiert. In derselben bezengte er mit den Vorstehern der beiden Prämonstratenserstifter Cappenber: und Knechtsteden, Hermann und Heribord ${ }^{2}$ ), welche inzwischen ebenfalls den Titel Abt angenommen batten ${ }^{3}$ ), dass der Er\%bischof Philipp I. von Heinsberg dem Kloster Meer den Erwerb voll Giitern bestätigt hatte ${ }^{4}$ ).

Welchen Umfang der Besitzstand der nenen Abtei Steinfeid unter Alberts Regierung erreicht hatte, ergibt sich aus einer von demselben Erzbischof im Jahre 1187 auf einer Synode zu Köln alsirestellten Urkuude, welche einzeln aufzählt: die im Hofe des Abteigebändes gelegene Pfarrkirche zum hl. Andreas mit allen ihren Zehnten und innerhalb der Pfarrgrenzen einen jäbrlichen Zins von 11 Mark, die ganze Ortschaft $W^{5}{ }^{5}$ ) im Kreise Mayen mit der Pfarre und allen ihren Zehnten, die Pfarre Ripsdorf ${ }^{6}$ ) im Kreise Schleiden mit allen ihren Zehnten, die Hälfte der Ort-

1) Die Angabe bei L. Goovaerts, Ecrivains, artistes et savants de l'ordre de Prémontré. Bruxelles 1899, p. 17, sowie in den Farramines Gelenii XXI, p. 138 (Handschrift auf dem Stadtarchiv zu Köln), dass Albert erst im Jahre 1194 erwählt wurde, ist falsch, wie sich aus der folgenden Urkunde ergibt.

2) Die Steinfelder Kirche feierte später sein Gedächtnis am 29. A pril. S. F. X. Boos, Eufalia. Heft III. Trier 1829, S. 48.

3) Auch die Prämonstratenserpropstei Hamborn im Kreise Ruhrort, zu welcher das Steinfelder Stift Beziehungen unterhielt, war um das Jahr 1180 zur Abtei erhoben worden. S. W. Fabricius, Erläuterungen num geschichtlichen Atlas der Rheinprovinz. 1. Hälfte: Die Kölnische Kirchenprovinz. Bonn 1909, ১. 252. Gleichwohl nahmen die Kappenberger Stiftsvorsteher später wieder den Titel Propst an. Während nachweislich noch in den Jahren 1196 bis 1210 ein Abt (Hermann) dem Stifte vorstand, traten dessen Nachfolger das ganze 13. Jahrhundert hindurch urkundlich immer als Pröpste auf. S. Th. J. Lacomblet, Urkundenbuch für die Geschichte des Niederrheins. 4. Bd. Düsseldorf 1858, S. 789 Nr. 642. R. Wilmans, Westfälisches Urkundenbuch. 3. Bd. Münster 1859, S. 33 Nr. 62. S. 42 Nr. 81 (und zahlreiche andere Belegistellen, auf welche der Index s. v. Cappenberg hinweist).

4) S. Lacomblet a. a. O. I, S. 349 Nr. 496. R. Knipping, Die Regesten der Erzbischöfe von Köln im Mittelalter. 2. Bd. Bonn 1901, S. 245 Nr. 1252.

5) S. Annalen 93, S. 48.

6) S. Fabricius a. a. O. S. $167 \mathrm{f}$. 
schaft Berndorf ${ }^{1}$ ) im Kreise Daun mit der Pfarre und allen ihren Zelnten, ferner Weinberge an der Mosel in den Ortschaften Croer, Rezre (Reil?), Ediger und Poltersdorf, sowie Weinberge in den Ortschaften Ahrweiler, Hemmessen und Wadenheim ${ }^{2}$ ), Lanters. hoven"), Bachem bei Ahrweiler, Birgel bei Remagen, Gunters. dorf, Franken ${ }^{4}$ ) im Kreise Ahrweiler, Waldorf und Fressen in Kreise Mayen ${ }^{5}$ ), ferner einen Hof in Willerseheid im Kreise Rheinbach (Pfarre Mutscheid), einen Zins von 32 Scbillingen in Stritterhof bei Marmagen (Kreis Schleiden), einen Hof Sleitholz (?), einen Zins von 16 Scbillingeu in Heistert im Kreise Schleiden, mehrere Hufen in Reipach ${ }^{6}$ ) bei Call, in Nettersbeim (Kreis Schleiden) einen Zins von 29 Schillingen, den Herrenhof Marmagen mit 12 Hufen, in Herle (Herl im Landkreise Trier?) einen Zins von 10 Schillingen, einen Hof in Wallenborn im Kreise Daun, 5 Hufen in Wahlen (Kreis Schleiden), einen Hof in Lutgenrode (Luickerath?), in Igeze (Igel im Kreise Trier?) einen Zins . von 16 Schillingen, in Gorgendorf (Gondorf im Kreise Mayen?) einen Zins von 2 Mark, in Misteden (Miesenbeim im Kreise Mayen?) einen Zins von 16 Schillingen und endlich je einen Hof in Zitlpich ${ }^{7}$ ), Bessenich $^{8}$ ) und Oberbolheim ${ }^{9}$ ) im Kreise Düren mit allem beweg. lichen und unbeweglichen Zubehör, wie Hofstätten, Gebäulichkeiten, Hofgesinde, Äckern, bebauten und unbebauten Ländereien, Wäldern, Tiergehegen, Bächen, Mühlen und jährlichen Einkünften, welche die Steinfelder Chorberren sich käuflich erworben oder die Gläubigen in ibrem frommen Sinne geschenkt hatten ${ }^{10}$ ).

1) S. ebenda S. 158.

2) Uber Hemmessen und Wadenheim s. J. F. Schannat, Eiflia illustrata oder geographische $u$. historische Beschreibung der Eifel, heransgegeben von G. Bärsch. 3. Bd., 1. Abt., 1. Absch. Aachen u. Leipzig 1852, S. $458 \mathrm{ff}$.

3) S. Annalen 20, S. 390.

4) S. Fabricius a. a. O. S. 136.

5) Vermutlich sind die Höfe Waldorf und Fressen in der Pfarre Ochtendung gemeint. S. Handbuch des Bistums Trier, herausgegeben vom bischöflichen Generalvikariat zu Trier. Trier 1912, S. 254.

6) S. Schannat-Bärsch a. a. O. 3. Bd., 1. Abt., 1. Absch., S. $67 \mathrm{f}$.

7) S. Fabricius a. a. O. S. $236 \mathrm{f}$.

8) S. ebenda S. 216.

8) S. Zeitschr. des Aachener Geschichtsvereins 6, S. $134 \mathrm{f}$.

10) S. J. Hartzheim, Concilia Germaniae. Tomus III. Coloniae Augustae Agrippinensium 1760, p. 438 sq. Knipping a. a. O. II, S. 253 f. Nr. 1282. 
Über Albert ist durch Überlieferung nur bekannt, dass er sich durch eine besondere Liebe $z \mathfrak{u}$ der allerseligsten Jungfrau ansgezeichnet und ein Buch De gaudiis $B$. Mariae virginis verfasst hat ${ }^{1}$. Er starb, wie ein auf diese seiue schriftstellerische T'ätigkeit anspielendes Chronodistichon in der series praepositorum et abbatum Steinfeldensium ${ }^{2}$ ) angibt, im Jahre 1189:

VItIs fLos abIIt, qVI propter gaVDIa sCrIpta VIrgIneae fVerat gratVs oDore rosae ${ }^{3}$ ).

\section{Abt Erenfried (1189-1209?).}

Der Güterbesitz erfuhr unter dem unmittelbaren Nachfolger Alberts durch Schenkungen und Kauf eine beträchtliche Erweiterung. Es schenkte der Graf Theodorich von Hochstaden ${ }^{4}$ ) mit seinem Sohne Lothar im Jahre 1194 der Abtei die Hälfte des Patronatsrechts in der Pfarre Hochkirchen im Kreise Düren und die Hälfte des Pfarrzehnten, sowie den von allen Abgaben freien Stadelhof ${ }^{5}$ ). Als Gegenleistung für den ihr gewährten Zehnten hatte die Abtei gemäss der allgemeinen Auffassung, dass der Pfarrer die Pflicbt habe, der Gemeinde das Zuchtvieh zu stellen ${ }^{6}$ ), einen Stier zur Deckung der Gemeindekühe der Pfarre Hochkirchen zu halten, während die Gemeinde den Stier weiden und Iiuttern musste ${ }^{7}$ ).

In einer zweiten, aus demselben Jahre (1194) datierten Urkunde, welche eine längere Fassung aufweist, fügte der Graf

1) S. D. Sammarthanus, Gallia christiana in provincias ecclesiasticas distributa. Tomus III. Parisiis 1725, col. 1175. Farragines Gelenii (im Kölner Stadtarchiv) XXI, S. 138.

2) S. die Handschrift im Staatsarchiv zu Düsseldorf A. 169 (jetzt R. 46) Pp. 40. 18. Jahrhundert (ohne Seitenzahl).

3) Die Steinfelder Kirche feierte gemäss ihrem alten Nekrologium Alberts Gedächtnis am 26. Januar (Series praep. et abb. Steinf.), die Abtei Rommersdorf hingegen am 18. Juni. S. J. Wegreler, Die Prämonstratenserabtei Rommersdorf. Koblenz 1882, S. 94.

4) S. Schannat-Bärsch a. a. O. 1. Bd., 1. Abt., S. 159.

5) S. Fabricius a. a. O. S. $34 \mathrm{f}$.

6) S. F. X. Künstle, Die deutsche Pfarrei und ihr Recht zu Ausrang des Mittelalters. Stuttgart 1905, S. $88 \mathrm{f}$. Diese Auffassung wird in der Urkunde direkt ausgesprochen: ratione medietatis dictae decimae.

7) S. Lacomblet a. a. O. I, S. 379 Nr. 544. Annalen 65, S. 221 . Knipping a. a. O. II, S. $296 \mathrm{Nr}, 1474$.

Anualen des hist. Vereins $\mathrm{XCV}$ 
Theodorich noch hinzu, dass die Abtei, abgeseben von der Stellung des Stieres, auch die Pflicht übernehmen musste, das Dach des Schiffes der Kirche stets in dem erforderlichen guten Zustande zu erhalten gemäss dem im Dekanate Bergheim ${ }^{1}$ ) herrschenden Brauch. Und da noch andere Fürsten und Herren, wie die Grafen von Jülich, Wickrath nnd Kenten, in der Pfarre Hochkirchen einige Teile des Zehnten rechtmässig in Besitz hatten, erklärte der gräfliche Geschenkgeber ausdrücklich, um Streitigkeiten zu vermeiden, dass er durch seine Schenkung nur die ibm zustehende Hälfte des Zehnten an die Abtei übertragen habe, obne in die Rechte anderer eingreifen zu wollen ${ }^{2}$ ). Die vollzogene Schenkung - genannt ist die Hälfte des Patronatsrechts, eine Hofstätte und der balbe Zehnte zu Hocbkirchen - wurde noch in demselben Jahre von dem Erzbischof Adolf I. urkundlich bestätigt ${ }^{3}$ ).

Im Jahre 1201 schenkten Hermann von Nideggen mit dem Beinamen Scavespan und seine Fran Beatrix dem Kloster Stein. feld 12 Mark zum Ankauf eines Grundstückes vor dem Tore seines Hofes in Ahrweiler. Da dasselbe noch unbebant war, wurde ihnen für den Fall, dass sie später in Not gerieten und entschlossen waren, von dem Kloster eine Unterstützung anzunehmen, der jährliche Ertrag eines Weinberges in Heimersheim angewiesen, der hinter dem Theater (hoc est spilbus) gelegen war. Ausserdem versprachen ihnen der Abt Erenfried und die Senioren des Klosters auf Treue und Glauben, dass sie in Steinfeld Aufnahme finden könnten, wenn einer der beiden Ehegatten nach dem Tode des anderen Teiles im Kloster Unterkunft suchen wolle, allerdings unter der Voraussetzung, dass fitr den Lebensunterhalt der Frau in entsprechender Weise gesorgt sei $^{4}$ ). Schliesslich ge-

1) Die Pfarrei Hochkirchen gehörte damals zum Dekanate Berg. heim, während sie gegenwärtig zum Dekanat Düren gerechnet wird. S. Fabricius a. a. O. S. 34 f. Vgl. Annalen 82, S. 135.

2) S. Lacomblet a. a. O. IV, S. $788 \mathrm{Nr} .640$.

3) S. Annalen 65, S. 221 f.

4) In welches rechtliche Verhältnis die Witwe alsdann zum Steinfelder Kloster trat, wird in der Urkunde nicht gesagt (si . . voluerit se transferre ad religionem, quod tutum regressum et ingressum habeat ad praedictam domum [Steinfeld]). Dass die Verieihung einer Präbende für niedere Kirchendienste an Frauen bis über das Jahr 1235 hinaus an einer Kollegiatkirche nachweisbar ist, s. P. Joerres, Urkundenbuch 
lobten die Geschenkgeber, den Überfluss ihrer Güter lastenfrei dem Kloster zuzuwenden, so dass nach ihrem Tode niemand eine Rente $z u$ fordern berechtigt sei, und fügten zu der früberen Schenkung noch 18 Mark hinzu ${ }^{1}$ ).

Kraft eines Kaufvertrages übernahm der Abt Erenfried von dem Propste Conrad und dem Dechanten Hermann des St. Adalbertstiftes in Aachen im Jahre 1196 die Mühle auf dem Hofe Oberbollheim $^{2}$ ) für eine jährliche Rente von 20 Maltern Mehl und 4 Schillingen, mit der Massgabe, dass die Hälfte der Fruchtabgabe an den Festen des hl. Martinus (11. Nov.) und der Apostel Philippus und Jacobus (1. Mai) entrichtet werde, während die Hälfte des baren Geldes am Feste des hl. Andreas (30. Nov.) und am Gründonnerstag fällig war. Ausserdem musste das Kloster bei dem Tode seines Abtes an den genannten Hof $1 / 2$ Mark ablicfern und an den Vogt des Hofes jährlich 1 Malter Malz, eine Naturalleistung, durch welche es von allen Verpflichtungen gegen die Gerichtsvogtei befreit wurde, es sei denn, dass es sich um Streitigkeiten bandelte, in denen es für seine eigenen Rechte eintreten musste ${ }^{3}$ ).

Von solchen Streitiglkeiten blieb die Steinfelder Abtei nicht immer verschont. Die Grossen des Landes, welche mit Neid und Eifersucht auf ibren wachsenden Besitz und steigenden Einfluss schauten, versuchten wiederholt in ihre Rechte einzugreifen oder ibre Güter an sich zu reissen. So sab sich der Abt Erenfried

des Stiftes St. Gereon za Köln. Bonn 1893, S. 103. H. Schaefer, Pfarrkirche und Stift im deutschen Mittelalter. Stuttgart 1903, S. 95.

1) S. Annalen 23, S. 158. Mitteilungen aus dem Stadtarchiv von Köln, herausgegeben von C. Höhlbaum. 3. Heft, Köln 1883, S. 11 f.

2) Der Hof selbst wird schon in der Urkunde des Erzbischofs Philipp vom Jahre 1187 als Eigentum des Steinfelder Klosters erwähnt. S. oben S. 64 .

3) Die von dem Abte Erenfried und seinem Prior Adam über den getätigten Vertrag ausgefertigte Urkunde s. Chr. Quix, Codex diplonaticus Aquensis. Tom. I, Pars I, Aquisgrani 1839, p. 46 sq. Nr. 68. Aus dem Steinfelder Konvente waren bei dem Akte ausser dem Abt und dem Prior als namentlich Genannte der Subprior Everhard, der Kellermeister Hermann, der Kantor Waldever, der Kustos Heinrich und die Laienbrüder Elger und Thomas zugegen. S. ebenda. Die Urkunde des Propstes Conrad und des Dechanten Hermann des Adalbertstifts ïber denselben Gegenstand s. Annalen 23, S. $154 \mathrm{f}$. Mitt. a. d. Stadtarchiv 3 , S. 11 . 
genötigt, den Grafen von Blankenheim, welche der Abtei den Neubruchszehnten von dem Walde bei Schleiden entziehen wollten, mit aller Schärfe entgegenzutreten. Da insbesondere der Graf Gerhard II. ${ }^{1}$ ) zur Rechtfertigung seines Vorgehens sich darauf berief, dass der Erzbischof Bruno III. von Berg (1191-1193) ihm denselben übertragen habe, begab sich der Steinfelder Abt mit der Bitte um Klarstellung der Sachlage persönlich zum Kölner Oberhirten, der inzwischen wegen seines hohen Alters und seiner geschwächten Gesurıdheit sein Amt niedergelegt und sich als Mönch in das Zisterzienserkloster Altenberg zurückgezogen hatte. Der Erfolg der Reise blieb nicht aus. Denn sofort machte Bruno in einen Schreiben an seinen (erwählten, aber noch nicht bestätigten) Nachfolger Adolf I. von Altena (1193-1205) öffentlich bekannt, dass die Aussage des Grafen Gerhard falsch sei, dass er weder ihm noch irgendeinem anderen jemals den in Rede stehenden Zehnten verliehen habe ${ }^{z}$ ).

Mit dieser Erklärung des Erzbischofs war der Streit aber keineswegs aus der Welt geschafft. Noch nngefähr fünf Jahre lang $\left.(1193-1198)^{3}\right)$ machten beide Parteien ibre Ansprüche nachdrücklich geltend. Als aber die beiden Brüder Gerhard und Conrad von Blankenheim zur Tat übergingen und den Zehnten wirklich an sich rissen, riefen die Steinfelder Chorberren die Hilfe des Erzbischofs Adolf an und beschwerten sich wiederholt bei den Prioren, d. h. den Leitern der Kölner Kollegiatkirchen ${ }^{4}$, und den Baronen des Landes. Sie erzielten damit die auf Grund eingehender Erkundigungen erfolgte urkundliche Feststellung seitens des Erzbischofs ${ }^{5}$ ), dass die beiden gräflichen Brüder seinen

1) S. Schannat-Bärsch a. a. O. 1. Bd., 1. Abt., S. 224.

2) S. die Urkunde im Schleidener Kopiar, saec. XV, f. 1 (Steinfeld Akten 12 a), Staatsarchiv zu Düsseldorf. Knipping a. a. O. II, S. 294 Nr. 1463.

3) Da Adolf seit dem 1. März 1194 urkundlich nicht mehr als electus, sondern als archiepiscopus auftritt, muss der erwähnte Brief Brunos vor diesem Termin geschrieben sein. S. Knipping a. a. O. II, S. $296 \mathrm{Nr} .1473$.

4) S. Schaefer a. a. O. S. 130. Über die Zusammensetzung des Kölner Prioren-Kollegiums im 13. Jahrhundert s. H. Cardauns, Konrad von Hochstaden, Erzbischof von Kölı. Köln 1880, S. 80.

5) Die Fürsorge des Erzbischofs Adolf für klösterliche Genossenschaften, insbesondere sein energisches Einschreiten gegen die Ubergriffo 
Vorgänger Bruno gebeten hatten, ihnen den Neubruchszehnten in dem Walde bei der Burg Schleiden als Lehen zu übertragen, eine Bitte, welche der Erzbischof unter dem ausdrücklichen Vorbehalt erfüllt hatte, dass er rechtlich dazu befugt und der Zebnte faktisch frei sei. In Wirklichkeit aber hatten bereits der Erzbischof Friedrich I. sowie mehrere seiner Vorgänger und alle seine Nachfolger bis auf Bruno III. dem Steinfelder Kloster nach Ausweis der ihm gewäbrten Privilegien den Neubruchszehnten bereitwillig znerkannt, und das Kloster war seit ungefähr 100 Jahren im ruligen Besitz desselben geblieben.

Gestïtzt auf diese festgestellten Tatsachen schloss der Er\%bischof nach dem Urteil der Prioren und mit Zustimmung des Adels den Grafen Conrad, den Begründer der gräflichen Linie scbleiden, dem bei der Teilung der Blankenheimer Erbgüter mit dem Schlosse Schleiden auch der umstrittene Zebnte zugefallen war ${ }^{1}$ ), aus der Kirchengemeinschaft aus. Und da die Chorherren auch auf einer Kölner Generalsynode die Angelegenheit zur Sprache brachten und von verschiedenen gelehrten Schulen, denen sie das gesamte Aktenmaterial unterbreiteten, das übereinstimmende Erkenntnis erbielten, dass der ganze Zehnte ibnen nach kirchlichen Rechte zukommen müsse ${ }^{2}$ ), sprach der Erzbischof die lxkommunikation über Conrad und alle seine Begünstiger noch einmal aus und befahl dem Vogte des Steinfelder Klosters, dem (rrafen Lothar von Hochstaden ${ }^{3}$ ), in Zukunft dasselbe durch Ausiibung seiner weltlichen Gewalt zu schützen.

gewalttätiger Grossen, obwohl sein Sinnen und Trachten mehr auf Krieg und Politik als die Erledigung kirchlicher Aufgaben gerichtet war, s. bei C. Wolfschlaeger, Erzbischof Adolf I. von Köln als Fürst und Politiker, Münster (Westf.) 1905, S. $18 \mathrm{f}$.

1) S. Schannat Bärsch a. a. O. 1. Bd., 1. Abt, S. 6555.

2) Dass die juristischen Studien im unmittelbaren Zusammenhang mit den Künsten des Triviums in den mittelalterlichen Kloster- und Stiftsschulen betrieben wurden, s. F. A. Specht, Geschichte des Unterrichtswesens in Deutschland von den ältesten Zeiten bis zur Mitte des 13. Jahrhunderts. Stuttgart 1885, S. $190 \mathrm{ff}$.

3) Das Schloss Are, dessen Besitzer gemäss einer Anordnung des Erzbischofs Friedrichs I. vom Jahre 1121 die Vogteigewalt über das Kloster Steinfeld besass, war damals das gemeinsame Eigentum der Grafen von Are und Hochstaden. 1205 setzte sich Lothar von Hochstaden gewaltsam in den Alleinbesitz der starken Festung und behauptete sich in ihr. S. Annalen 93, S. 21 ; Cardauns a. a. O. S. 63. 
Unterdes kam zwischen den streitenden Parteien durch die Vermittlung der (Grafen Walram vou Montjoie ${ }^{1}$ ) und Gerhard von Reifferscheid ${ }^{2}$ ) eine Aussöhnung zustande, indem Conrad freiwillig seinen Ansprüchen entsagte und die Erklärung abgab, dass weder er noch irgendeiner seiner Verwandten das Kloster in Zukunft wegen des Zehnten belästigen werde. Infolgedessen bestätigte der Er"zbischof nach dem Beispiele seiner Vorgänger dem Kloster im Jahre 1198 von neuem den gesamten Neubruchszebnten in dem ganzen Bereiche seines Pfarrbezirkes, soweit derselbe in der Kölner Erzdiözese gelegen war ${ }^{3}$ ).

Zehn Jahre später (1208) hatte Erenfried Gelegenheit, den Klosterbesitz abermals zu vermehren. Der Graf Lothar von Hochstaden, der Sohn Theodorichs, schenkte der Kirche von Steinfeld, welche durch ihn und um seinetwillen schwere Verluste und viele Belästigungen erlitten habe, das seiner Familie erblich zustehende Patronatsrecht über die Kirche in Mersburden ausserhalb der Ortschaft Zülpich (ad portam Martis) ${ }^{4}$ ), und der Erzbischof Theoderich von Hengebach (1208-1212) bestätigte in der Kollegiat. kirche zum hl. Andreas in Köln in Gegenwart des Abtes und des Priors von Steinfeld die vollzogene Schenkung. Gleichzeitig gab der Graf bekannt, dass das Kloster mit seiner Zustimmung 42 an sein freies Gut in Hochkirchen angrenzende Morgen Land, mit welchen bisher der Ritter Gerhard belehnt war, von diesem für 42 Mark gekauft und er alle Lehensrechte, welche aus diesem Besitze entsprangen, freiwillig an das Kloster abgetreten babe ${ }^{5}$ ).

War der Abt Erenfried bemüht, die materiellen Interessen seines Klosters mit Eifer und Geschick zu vertreten. so hielt er sein Augenmerk doch vor allem auf die religiös-sittliche Hebung desselben gerichtet. Wie sehr der Steinfelder Konvent unter seiner Leitung innerlich erstarkt und äusserlich gewachsen war, beweist

1) S. Schannat.Bärsch a. a. O. 1 Bd., 2. Abt. S. 603.

2) S. ebenda S. 620 .

3) S.C.L.Hugo, Probationes secundi tomi monasteriologiae Praemonstratensis. Nanceii 1736, col. 524 sq. Knipping a. a. O. II, S. 318 Nr. $155 \%$.

4) S. Fabricius a. a. O. S. 236 f. Mersburden = St. Martinsbauerschaft. S. Zeitschr. des Aachener Geschichtsvereins 1, S. 74; 11, S. $117 \mathrm{f}$. I. G. Broix, Erinnerungen an das alte berühmte Tolbiacum. Neuss 1842, S. 86 .

5) S. Hugo, l. c. col. 526. Kuipping a. a. O. III, S. 11 Nr. 57. 
lie Tatsache, dass er, ohne für sich eine wesentliche Beeinträchtìnung befürchten $z \mathfrak{n}$ müssen, aus seiner Mitte zwölf Chorherren mit einem Vorsteher an der Spitze zur Gründung einer neuen klüsterlichen Niederlassung aussenden konnte.

Dieselbe war von dem Grafen Heinrich von Sayn, dem Schirmvogt der Kölner Kirche, welcher bereits im Jahre 1185 mit dem Steinfelder Abte Albert und 1198 mii seinem Nachfolıer Erenfried in Köln persönlich zusammengetroffen war ${ }^{1}$ ), zwei Stunden nördlich von Koblenz auf der rechten Rheinseite errichtet und mit Gütern reich ansgestattet worden. Nachdem (ler päpstliche Legat Guido, Bischof von Palästrina, der seit 1201 in Deutschland weilte ${ }^{2}$ ), im folgenden Jabre die Klosterkirche konsekriert und die Stiftung bestätigt hatte, erklärte der Erzlıschof Johann I. von Trier in einer erneuten Bestätigungsurkunde, in welcher der Abt Erenfried als Zeuge auftrat, dass das neue Kloster das Tochterverhältnis und die Pflicht der Unterordnung unter das Mutterkloster Steinfeld stets anzuerkennen habe"). So taaten noch in demselben Jahre zwölf Chorberren aus Steinfeld unter Leitung des Propstes Hermann, den sie als solehen sich

1) S. Lacomblet a. a. O. I, S 349 Nr. 496; S. 393 Nr. 564.

2) S. J. F. Böhmer, Regesta Imperii V. 2. Bd., Inrsbruck 1892-1894, i. $1516 \mathrm{Nr}$. 9975. C. Eubel, Hierarchia catholica medii aevi, $\mathrm{I}^{2}$, Monasterii 1613, p. 37.

3) S. J. N. ab Hontheim, Historia Trevirensis diplomatica et pragmatica. Tomus I, Angustae Vind. et Herbipoli 1750, p. b41 sqq. Die Stiftung wurde durch eine Bulle vom 4. Mai 1206 auch vom Papste Innocenz III. bestätigt. S. ibid. p. 644 sqq. A. Potthast, Regesta pontificum Romanorum. Vol. I, Berolini 1874, S. 237 Nr. 2767. Vgl. Annalen 3, $\therefore$. $78 \mathrm{f}$. Gemäss der Uberlieferung warde ungefähr um dieselbe Zeit (1.04) von Steinfeld aus das Prämonstratenserkloster Dockum in Friesland gegründet, und zwar an der Stelle eines ehemaligen Chorherrenstiftes, aus dem der Geist der Frömmigkeit und klösterlichen Zucht mewichen war. S. C. L. Hugo, Sacri et canonici ordinis Praemonstratusis annales. Tomus I, Nanceii 1734, col. 617. Derselbe, Sacrae antiquitatis monumenta historica, dogmatica, diplomatica. Tomus I, Stivagii 1725, p. 431. Indessen sind über die Gründung und die älteste Geschichte des Klosters keine urkundlichen Nachrichten erhalten. Die erste Urkunde, welche überhaupt des Prämonstratenserstifts Dockum Erwähnung tut, ist vom Papste Honorius III. am 8. April 1224 ausgefertigt. S. G. Brom, Bullarium Trajectense. Fasciculus I, Haga-Comitis 1891, S. 41 Ni. 107. 108. 
erwählt hatten, die Reise in ihr nenes klösterliches Heim nach Sayn an und organisierten sich dort in kürzester Frist zu einem so starken und lebenskräftigen Konvente, dass die Erhebung des Klosters zur Abtei vom Mutterkloster bald ins Auge gefasst wurde.

Wegen dieser Tochtergrüudung in Sayn geriet die Abtei Steinfeld in ein heftiges Zerwürfnis mit der Abtei Rommersdorf und deren Abte Reiner, die in ibrem Unwillen darüber, dass die neue Stiftung obne ihre Zustimmung erfolgt war und nun sogar zur Abtei erhoben werden sollte, hauptsächlich geltend machten, dass die beiden Orte Rommersdorf und Sayn zu nahe beieinander gelegen seien, da nach den Ordensstatuten jede Abtei mindestens vier Stunden von der anderen entfernt sein müsse $\left.{ }^{1}\right)$. Aber im Jahre 1204 wurde die strittige Angelegenheit auf dem General. kapitel in Prémontré in der Weise beigelegt, dass die Chorherren von Rommersdorf sich grundsätzlich mit der Errichtung des Klosters Sayn und seiner Erhebung zur Abtei einverstanden erklärten, während die Chorherren von Sayn sich verpflichteten, die Vorschriften genau zu beachten, welche ihnen in bezug auf die Feier des Gottesdienstes, den Erwerb von Eigentum und die Hut von Zuchttieren auferlegt wurden ${ }^{2}$ ).

Wie die Abtei Steinfeld mit dieser Tochtergrïndung wegen des geschaffenen Abhängigkeitsverhältnisses in einer beständigen Beziehung blieb, so trat sie auch in eine dauernde Verbindung zu dem Prämonstratenserinnenkloster Reichenstein in der Eifel, welches von dem Herzog Walram von Limburg und Falkenburg, Herrn von Montjoie, und seiner Gemablin Jutta durch Umwandlung ibrer Burg im Jahre 1205 gegründet und mit reichen Einkünften beschenkt worden war $^{3}$ ).

1) S.E. Martène, De antiquis ecclesiae ritibus. Tomus III, Antverpiae 1737, col. 921 .

2) S. Mittelrheinisches Urkundenbuch II, S. 256 ff.; Wegeler a. a. O. S. 11 .

3) Die Gründungsgeschichte dieses Klosters bedarf noch sehr der Aufhellung. Bereits der Propst Ulrich von Steinfeld (1152-1170) erwähnte in einem seiner Briefe ein Kloster des Namens Reichenstein (Richwinstein) und bezeichnete es als Doppelkloster für Männer und Frauen (fratres et sorores qui ibi sunt). Ob dieses später in ein Prä. monstratenserinnenkloster umgewandelt wurde und mit dem von dens Herzog Walram gestifteten identisch ist, wird sich schwerlich ermittein lassen. S. Roth a. a. O. S. 304; Annalen 94, S. 26. 
Nachdem der Erzbischof Bruno IV. von Sayn (1205-1208) aus dem Prämonstratenserinnenkloster Heinsberg die Professschwestern Irmgardis, Hedwig und Luitgardis sowie die Laiensclwester Lucarda in die neue Niederlassung eingeführt und ihr Irmgardis als Meisterin vorgesetzt hatte, übertrug sein Nachfolger Dietrich im Jahre 1208 auf Bitten der Schwestern die Ausübung der ständigen Seelsorge im Kloster der Steinfelder Abtei, weil es wegen der weiten Entfernung von Köln nicht empfehlenswert erschien, einen Rektor mit diesem Amte zu betrauen, welcher jeden Augenblick abgerufen werden konnte ${ }^{1}$ ). Somit trat zu den heiden Prämonstratenserinnenklöstern, welche innerbalb der Erzdiözese Köln der Leitung des Steinfelder Abtes unterstanden, D) inwald und Meer, fortan Reichenstein als drittes hinzu.

Für das Kloster Dünwald, die älteste Tochtergründung von steinfeld, traf Erenfried im Jahre 1192 eine Massnabme, welche eine C̈bertragung von Gütern zum Zwecke hatte, aber in ihren Einzelleiten nicht bekannt ist. Die Handschrift Monasteria monialium sub Steinfeld (im Stadtarchiv zu Köln) deutet sie mit den Worten an: Vide literas domini Herenfridi abbatis Steinfeldensis, in quibus curtern Dunwaldensem transfert in Hermannum de Bilke ${ }^{2}$ ). Im März des Jahre 1202 gab Erenfried mit dem Abte Johann I. von Floreffe ${ }^{3}$ ) seine Zustimmung dazu, dass die Prämonstratenserinnen in Schillingskapellen ${ }^{4}$ ) im Kreise Rheinbach, die der Leitung jenes Abtes anvertraut waren, ibre bei Remagen gelegenen Weinberge mit denen des Dünwalder Klosters in Grau-Rheindorf und Bornheim vertauschten. Die über den Tauschvertrag ausgefertigte Urkunde, in welcher der Prior Gerhard und der Kellermeister Conrad aus Dtunwald als Zeugen auftraten, bekräftigte er durch die Anhängung seines Siegels ${ }^{5}$ ).

1) S. M. S. P. Ernst, Histoire du Limbourg. Tomus VI, Liège 1847, p. 171. Knipping a. a. O. IJI, S. 12 Nr. 58.

2) S. Annalen 44, S. 108. Item in literis domini Herenfridi abbatis Steinfeldensis, quibus transfert curtim Dunwaldensem prope s. Aprum (?) in Hermannum Bilke de anno 1192. S. ebenda S. 112.

3) S. Dom Ursmer Berliére, Monasticon belge. Tome I. Abbaye de Maredsous 1890-1897, p. 114. V. Barbier, Histoire de l'abbaye de Floreffe. 'Tonie I. Namur 1899, p. 87 sqq.

4) S. Annalen 32, S. 133 ff. Fabricius a. a. O. S. 138.

5) Annalen 44, S. $49.68 \mathrm{f}$. 
In dem Kloster Meer hatte Erenfried zweimal Veranlassung. Angelegenheiten materieller Art zu ordnen. Nachdem er schon im ersten Jahre seiner Regierung (1189) 16 Morgen Land, welche dem Kloster gehörten, gegen 16 andere Morgen der Kollegiatkirche zu den hl. Aposteln in Köln eingetauscht batte ${ }^{1}$ ), gab er im Jabre 1205 seive Genehmigung zu einer Stiftung, welche der Kellermeister und Kämmerer Hermann gemacht hatte, indem er aus dem Erlös der Weinernte in Wolsdorf bei Siegburg jährlich 60 Ellen Leinen zur Anfertigung von Tüchern, Kopfhüllen und Kleidern für die Schwestern bestimmte, ferner drei Schillinge für die Schwester, welche für die Kleider zu sorgen hatte, das ep. forderliche Öl zum Unterhalte mehrerer Lampen in der Kirche, in den Krankenbäusern der Schwestern und der Laienbrüder, und eine Pitanz von Weizenbrot, Fisch und Wein am Tage seines Jahrgedächtnisses ${ }^{2}$ ).

Über das Todesjahr und den Todestag des Abtes Erenfried gehen die Ansichten weit auseinander. Während der Annalist Hugo behauptet, derselbe sei vor dem Jahre 1208 aus dem Leben geschieden ${ }^{3}$ ), bält Becker mit seinem Urteil zurtick, da er ihn nur für die Jabre 1197 bis 1202 urkundlich nachweisen kann ${ }^{4}$ ). Es steht aber fest, dass der Erzbischof Theodorich, welcher dem Abte Erenfried die Verleibung des Patronatsrechts über die Kirche in Mersburden bestätigte und die Ansübung der Seelsorge in dem Kloster Reichenstein (ubertrug ${ }^{5}$ ), erst am 22. Dezember

1) S. die series praepositorum et abbatum Steinfeldensium in Staatsarchiv zu Düsseldorf. Hugo, Annales II, col. 854.

2) S. Lacomblet a. a. O. II, S. $10 \mathrm{f}$. Nr. 16. Dass Erenfried von geistlichen und weltlichen Fürsten öfters zu wichtigen Beratungen und Verhandlungen hinzugezogen wurde, s. ebenda I, S. $378 \mathrm{Nr} .541$; S. 385 Nr. 553 ; S. 393 Nr. 564 ; S. 399 Nr. 569; Mittelrheinisches UrlsundenbuchII, S. 213 f.; Annalen 23, S. 155 f.; 65், S. 2ž5. Utber den jhm vom Papste Innocenz III. erteilten Auftrag, in Verbindung nit dem Propste Hermann von St. Severin in Köln und dem Prior Gerhard von Meer in dem frei. herrlichen Franenstifte Gerresheim bei Düsseldorf eine Untersuchung. vorzunehmen, s. Migne, Patrologia latina CCXIV, col. 940 sqq; col. 1044 sqq.; Joerres a. a. O. S. 44 f.

3) S. Annales II, col. 854: Ante 1208 e vivis eum excessisse acta Everhardi testantur.

4) S. Nekrologium S. 203.

5) S. oben S. 70. 73 . 
1208 gewählt wurde ${ }^{1}$ ). Mithin konnte der Tod des Abtes erst nach diesem Termine erfolgen, frühestens in den letzten Tagen des Jahres 1208 oder im Beginn des folgenden Jahres, gemäss der in der Erzdiözese Köln ungefähr bis 1310 üblichen Berech. nung der Jabresdauer bis zum 25. Mărz. Da das alte Steinfelder Nekrologium das Gedächtnis seines Todes am 16. Februar cierte ${ }^{2}$ ), w ürde er unter der Voraussetzung, dass dieses Datum wirklich seinen Todestag angibt, nicht vor dem 16. Februar 1209 grestorben sein.

\section{Abt Eberhard (1209?-1211).}

$\ddot{\mathrm{C}}$ her den dritten Steinfelder Abt, welcher unter Erenfried das Amt des Subpriors ausgeübt hatte ${ }^{3}$ ), sind nur spärliche und \%. 'T. falsche Nachrichten erhalten. Wenn Hugo berichtet, Eberhard habe von dem Grafen Lothar von Hochstaden viele Bedrickungen erlitten, aber schliesslich seinen Gegner durch seine (ieduld besiegt und Gott habe dessen Herz so zur Zerknirschung und lBusse gerührt, dass der reuige Sünder die der Abtei zuyrefiigten Scbäden wieder gutmachte und dem Abt das Patronatsreclit iiber die Kirche in Mersburden abtrat ${ }^{4}$ ), so liegt bier offenhar eine Verwechslung mit seinem Vorgänger Erenfried vor ${ }^{5}$ ). IIs Regierungszeit Eberhards gibt Gelenius in seinen Farragines (XXI, p. 139; Stadtarehiv zu Köln) die Jahre 1226-1247 an. ther diese Angabe ist schon deshalb als falseh zu erachten, weil für seinen Nachfolger vom Jahre 1211 ab Regierungshandlungen nachweisbar $\operatorname{sind}^{6}$ ).

1) S. Knipping a. a. O. III, S. 9. Eine Urkunde des Erzbischofs, die noch aus dem Jahre 1208 datiert ist (pontificatus nostri anno primo), s. Lacomblet a. a. O. II, S. $14 \mathrm{Nr} .24$.

2) S. die series praep. et abb. Steinfeldensium. Die Abtei Arnstein hielt sein Jahrgedächtnis am 6. Dezember, die Abteien Prémontré, Sayn und Rommersdorf hingegen am 10. Dezember. S. R. van Waefelghem, L'obituaire de l'abbaye de Prémontré, Bruxelles 1909, p. 235 ; Becker, Velrologium S. 203; Wegeler a. a. O. S. 101.

3) S. oben S. 67 Anm. 3.

4) S. Hugo, Annales II, col. $854 \mathrm{sq}$.

5) S. oben S. 70 .

6) S. Hugo, Annales II, col. 85̄ō. Die Abteien Prémontré, Rommersdorf und Parc (bei Löwen in Belgien - diese besteht heute noch -) feierten sein Gedächtnis am 4, April. S. van Waefelghem l. c. p. 81; 


\section{Die Abtei Steinfeld in der ersten Hälfte des 13. Jahrhunderts.}

4. Abt Macarius $(1211-1247)$.

Während der Abt Eberhard nur kurze Zeit Gelegenheit gehabt hatte, den Abtstab in Steinfeld zu führen, war seinem Nachfolger Macarius eine sehr lange Regierungszeit beschieden. Indem er die materiellen Interessen des Hauses mit allem Nach. druck nach aussen vertrat und die religiös-sittlichen Aufgaben in der klösterlichen Innenwelt eifrig förderte, musste die Abtei auf dem Wege der planvollen, kräftigen Entwicklung, den sie seit ihrer Gründung mit Erfolg eingeschlagen hatte, rüstig weiter fortschreiten ${ }^{1}$ ).

Den Klosterbesitz vermehrte Macarius durch sechs nambafte Schenkungen, die er annehmen konnte, ohne der Abtei dafür eine wesentliche Gegenleistung auferlegen zu müssen. Der Dechant C. von Arberg ${ }^{2}$ ) und sein Bruder Hel. schenkten im Jahre 1212

Wegeler a. a. O. S. 92; R. van Waefelghem, Le nécrologe de l'abbaye du Parc, Bruxelles (ohne Druckjahr), p. 142. Wenn Eberhard in dem Totenregister des Mutterklosters Prémontré (p. 81) als fundator Winaugiensis, als Gründer des Prämonstratenserinnenklosters Wenau im Kreise Düren bezeichnet wird, so erweist sich auch diese Angabe als falsch, da das genannte Kloster bereits 1122 ron den Herren von Heinsberg. gestiftet und der Aufsicht des Abtes von Floreffe unterstellt war. S. Zeitschr. des Aachener Geschichtsvereins 4, S. 251; Berlière 1. c. p. 112.

1) Zur Zeit des Abtes Macarius lebte der selige Prämonstratenserchorherr Hermann Joseph, welcher, um das Jahr 1150 in Köln geboren, im Alter von 12 Jahren in Steinfeld das Kleid des hl. Norbert nahm und nach seiner Ausbildung im Steinfelder Tochterkloster Mariengarten in Steinfeld das Amt des Sakristans versah. Als echter Mystiker mit reicher Ge. müts- und Willenstätigkeit zeichnete er sich besonders durch die Gabe des beschanlichen Gebetes, durch die Tugenden der Demut und Abtötung und eine kindliche Liebe zur Gottesmutter aus. Nachdem er um das Jahr 1241 in dem Zisterzienserinnenkloster Hoven bei Zülpich, in welchem er während der Osterzeit seelsorgerische Tätigkeit ausübte, gestorben war, fand er seine Ruhestätte in einem prächtigen Marmorsarkophage im Mittelschiff der Abteikirche $\mathrm{zu}$ Steinfeld. Ich behalte mir vor, das über ihn vorhandene literarische Material später kritisch zu sichten und zu einer abgeschlossenen geschichtlichen Darstellung: zu verarbeiten.

2) Uber den Namen Arberg oder Arburg=Aremberg s. Fabricius a. a. O. S. 157 . 
jir Gut zu Lindweiler ${ }^{1}$ ) im Kreise Schleiden zu dem Zwecke, dass aus seiven Erträgen dem Konvente während der Fastenzeit fitr die Zubereitung der Speisen das nötige öl beschafft werde, und der Graf Lotbar von Hochstaden erklärte in seiner Eigenschaft als Vogt der Abtei ${ }^{2}$ ) das Gut urkundlich für dienst- und algabenfrei ${ }^{3}$ ).

Nachdem Hermann von Jünkerath der Abtei den achten Teil des Waldes, welcher an Malsbenden ${ }^{4}$ ) und Düttling ${ }^{5}$ ) im Kreise sichleiden angrenzte, zugleich mit dem Gute Malsbenden zum Geschenk gemacht hatte, tiberwiesen die Grafen Lothar von Are ${ }^{6}$ ) und Wilbelm III. von Jülich ${ }^{7}$ ) im Jahre 1213 ihr urkundlich den ihr rugefallenen Waldanteil ${ }^{8}$ ).

Die kinderlosen Eheleute Dietrich und Agnes von Malberg ${ }^{9}$ ) schenkten der Abtei im Jahre 1224 ihr Gut in Zeltingen an der Ilosel mit der Massgabe, dass zur Erinnerung an sie in der Kirche 2.11 Steinfeld beständig eine Lampe brennen und am Tage ibres Jahrgedächtnisses der Konvent aus den Erträgen des Gutes eine besondere Beköstigung erhalte. Für den Fall, dass ibre Ehe noch nit Nachkommenschaft gesegnet würde, sprachen sie ihren Kindern, wofern diese das Gut selbst besitzen wollten, das Recht $\mathrm{zu}$, es für 30 Mark zurückzukaufen ${ }^{10}$ ).

Im Jahre 1226 schenkte der Kölner Bürger Gerhard eine Hofstätte zu Abrweiler unter der Bedingung, dass ihm für die Zeit seines Lebens die Hälfte der Einkünfte verblieb und nach

1) S. ebenda S. 168.

2) S. oben S. 69.

3) S. Lacomblet a. a. O. IV, S. 793 Nr. 647. Der Erzbischof Johann I. von Trier, welcher am 14. oder 15. Juli 1212 starb, hatte der Steinfelder Abtei testamentarisch vermacht $X$ libras, ut de ipsis ordinetur, quod lumen ante maius altare die noctuque incessanter ardeat. s. Mittelrheinisches Urkundenbuch II, S. 330 Nr. 297.

4) S. Fabricius a. a. O. S. 229.

5) S. Schannat-Bärsch a. a O. 3. Bd. 1. Abt. 1. Abschn., S. 65.

6) S. ebenda 1. Bd. 1. Abt., S. 123. 126.

7) S. Zeitschr. des Aachener Geschichtsvereins 11. Bd., S. $100 \mathrm{ff}$.

8) S. Annalen 23, S. $159 \mathrm{f}$. Mitt. aus d. Stadtarchiv von Köln 3, S. 14. Aus Dankbarkeit feierte die Steinfelder Kirche das Gedächtnis des Geschenkgebers Hermann von Jünkerath am 28. April. S. Boos a. a. 0. 3. Heft, S. 48 .

9) S. Schannat-Bärsch a. a. O. 1. Bd. 2. Abt., S. $476 \mathrm{f}$.

10) S. Annalen 23, S. 161. Mitt. aus d. Stadtarchiv von Köln 3, S. 16. 
seinem Tode für ihn, seine Frau und seine Kinder drei Jahr. gedächtnisse gehalten würden ${ }^{1}$ ).

Der ebengenannte Graf Lothar von Are und seine Gemablin Margaretha schenkten der Abtei im Jahre 1229 eine Hufe z Claffenkotten, welche sie mit dem Burggrafen Heinrich von Aren. berg ${ }^{2}$ ) gegen die Abtretung seiner Reclte in Commern ein. getauscht hatten ${ }^{3}$ ).

Am 14. Juli 1240 übertrugen der Graf Arnold von Hückes. wagen ${ }^{4}$ ) und seine Gemablin Adele mit Zustimmung ihres Sohnes Franco in Gegenwart des Abtes Macarius und der beiden Stein. felder Chorberren Goswin und Gerhard durch Scbenkungsurkunde der Abtei ihre Besitzung in Rhöndorf am Drachenfels mitsamt den zugebörigen Weingärten und Äckern, Wäldern und Wiesen5).

Zu diesen Schenkungen gewann das Kloster im Laufe der Jahre durch Kauf bzw. jährliche Abgaben noch Hofstätten, Wein. berge und Ackerland hinzu. Der Abt Friedrich von Prïm verlieh ihm im Jahre 1228 eine Hofstätte neben dem Steinfelder Klosterhof in Alrweiler, welche bisher ein gewisser Gerhard als Leben besessen hatte, zum erblichen Besitz gegen einen jäbrlichen Zins von 2 Kölner Denaren und eine Abgabe von 18 Denaren jedesmal beim Tode eines Steinfelder Abtes ${ }^{6}$ ).

1) S. A. Tille, Übersicht über den Inhalt der kleineren Archive der Rheinprovinz. 1. Bd. Köln 1899, S. 167. Diese Urkunde vom Jahre 1226, sowie die weiter unten genannten Urkunden aus den Jahren 1228, 1229, 1238, 1295 habe ich leider nicht einsehen können. Der Bürgermeister von Siegburg-Menden, Herr von Claer, hatte die Güte, mir auf eine Anfrage mitzuteilen, dass dieselben sich nicht mehr in seinem Familienbesitze befänden, sondern durch Kauf in das Eigentum der Kölner Familie von Rautenstrauch übergegangen und jetzt nach seiner Ver. mutung in den Händen des Kommerzienrates Eugen von Rautenstrauch seien. Obwohl ich diesem Herrn persönlich einen Besuch machte und mich zweimal brieflich an ihn wandte, ist es mir nicht gelungen, einen Einblick in die Urkunden zu erbalten. Ich muss mich daher jedesmal auf die blosse Wiedergabe des von Tille gebotenen Inhaltes besehränken.

2) S. Schannat-Bärsch a. a. O. 1. Bd. 1. Abt., S. 184. Das Burggrafenamt war in der Familie der edelfreien Herren von Arenberg seit mindestens 1167 erblich. S. F. Lau, Entwicklung der kommunaleu Verfassung der Stadt Köln bis_zum Jahre 1396. Bonn 1898, S. $11 \mathrm{f}$.

3) S. Tille a. a. O. I, S. 167.

4) S. Zeitschr. des Bergischen Geschichtsvereins 25, S. 10.

5) S. Lacomblet a. a. O. IV, S. 800 Nr. 660.

6) S. Tille a. a. O. I, S. 167. 
Derselue Abt Friedrich ïbertrug dem Kloster im Jahre 1239 i) Eigentum 3 Morgen Weinberge, welche in Ahrweiler binter der Kirche gelegen waren, sowie eine in nächster Nähe bei dem steinfelder Hofe in Geroldshoven ${ }^{1}$ ) befiudliche Hofstätte. Da die steinfelder Kirche die Weinberge von dem Ritter Johann von Bachem, einem Getreuen des Klosters Prïm, erworben hatte, musste sie in jedem Jahre als Abgabe ein Paar Jagdstiefel nach Prüm liefern, während sie für die Hofstätte, welche sie von Gerhard von Ahrweiler, ebenfalls einem Getreuen des Prümer Klosters, rekauft hatte, jährlich ein Paar Socken zu entrichten batte ${ }^{2}$ ).

In Jahre 1241 kaufte das Kloster für $6 \frac{1}{4}$ Mark von dem Prior Hermann und der Meisterin Beatrix des Nonnenklosters viederebe in Kreise Daun $3 / 4$ Morgen Weinberge und einen yanzen Morgen Ackerland, welche hinter der Einfriedigung des steinfelder Hofes in Ahrweiler gelegen waren ${ }^{3}$ ).

Zur Abwehr ungerechter Angriffe auf die dem Kloster richterlich zuerkannten Einkunfte war Macarius, wie sein Vorgänger Erenfried, in die Notwendigkeit versetzt, mit Sehärfe regen den Grafen Conrad von Schleiden vorzugehen, welcher, uneingedenk seines im Jahre 1198 gegebenen Versprechens, mit nenen Ansprïcben auf den Neubruchzehnten in der Pfarre Steinfeld hervortrat. Obwohl der Graf ausdrücklich auf sein vermeintliches Recht verzichtet und erklärt hatte, dass er das Kloster wegen dieses Zehnten nicht mehr belästigen werde ${ }^{4}$ ), liess er sich ron dem Erzbischof Dietrich dennoch mit ihm belehnen.

Bei dieser Gelegenheit beschwerte sich das Kloster von neuem, weil es den Zehnten seit unvordenklichen Zeiten in Besitz gehabt hatte, und machte vor allem geltend, dass die Kapelle in Sistig ${ }^{5}$ ), an welcher der Zehnte haftete, eine Privatkapelle des Hofes sei, wenngleich zu ibr anch einige durch Schenkung er-

1) Die Besitzungen des Steinfelder Klosters in Geroldshoren werden bereits in dern Schutzbriefe des Papstes Innocenz II. vom Jahre 1136 nufgeführt. S. Annalen 93 , S. 30.

2) S. Mittelrheinisches Urkundenbuch III, S. $506 \mathrm{f}$.

3) S. Annalen 51, S. $158 \mathrm{f}$.

4) S. oben S. 70 .

5) Sistig bildete mit Steinfeld, Kall und Wildenburg die vier Seelsorgebezirke, in welche der Pfarrsprengel Stcinfelr eingeteilt war. S. Schannat-Bärsch a. a. O. 3. Bd. 1. Abt. 1. Abschn. S. 68. 145. Fabricius a. a. O. S. 174. 
worbene Ländereien gehörten, aus deren Erträgen die notwendigen Mittel für den Lebensunterbalt des Seelsorgsgeistlichen gewonnen würden (aliquas terras, quae vulgo mansus dotales appellantur). Nachdem Conrad im Gegensatze hierzu eine Zeitlang hartnäckig der Kapelle den Cbarakter einer Pfarrkircbe zagesprochen hatte (ecclesiam parochialem et baptismalem), gab er schliesslich doch nach und übertrug am 28. Januar 1214 den Kloster in Gegenwart seines Priors, des Pastors und Kellermeisters ohne allen Vorbehalt die Kapelle in Sistig sowie eine Hofstätte, welche früher der Kaplan bewohnte, ferner 2 Morgen Ackerland und eine Hufe, welche das Kloster sich nach Belieben aus den 60 Morgen im Walde bei Schleiden aussuchen konnte. Ausserdem schenkte er ihm, damit nicht seine Nachkommen eine neue Gelegenbeit zu Feindseligkeiten fänden, die Kapelle, welche sich in seiner auf Steinfelder Gebiet gelegenen Burg befand, verlieh ihm das Recht, nach freiem Ermessen in derselben durch einen Weltgeistlichen oder Ordensmann den Gottesdienst halten zu lassen, und verrichtete auf alle Zehnten, die früber und jetzt Gegenstand des Streites gewesen waren.

Da er im Begriffe stand, eine Wallfahrt nach Rom zu unternehmen, liess er vorläufig durch die anwesenden Priore seine Schenkung bestätigen und fügte hinzu, dass er nach seiner Rückkehr von Rom auch die Bestätigung des Erzbischofs einholen werde, wenn inzwischen die in der Kölner Kirche durch die Absetzung Dietrichs und die Wiedereinsetzung Adolfs entstandenen Wirren ${ }^{1}$ ) beigelegt $\operatorname{seien}^{2}$ ).

Drei Tage später (31. Januar) legte der Graf in reumütiger Gesinnung das Geständnis ab, dass er das Kloster Steinfeld wegen der eigenen Güter und auch der Gemeindebesitzungen, die in seinem Bezirke gelegen waren, sowie wegen einer Streitigkeit, die zwischen dem Kloster und den Leuten zu Sistig uber die Feier des Gottesdienstes entstanden war, in der Vergangenheit öfters ungerechterweise belästigt babe. Um für die Zukunft seinen Erben die Rechtslage genau zu bezeichnen, erklärte er urkundlich in Gegenwart des Priors und des Pastors der Steinfelder Kirche

1) S. Annalen 46 , S. 150 ff. Knipping a. a. O. III, S. $20 \mathrm{f}$.

2) S. Originalurkunde im Stadtarchiv zu Köln. An derselben haften vier seidene Schnüre; eine fünfte Schnur ist abgerissen. Die Siegel fehlen. Knipping a. a. O. IIJ, S. 19. 23. 
als Zeugen, dass er keinerlei Anspruch auf die Güter und die Leute des Klosters habe, die sich in seinem Bezirke befänden, während das Kloster das Recht der Mitbenutzung der Weiden, der Wälder und des Wassers besitze und dafür nur den Förstern jährlich 8 Sümmer ( $=2$ Malter) Hafer von seinem in der Nähe von Call gelegenen Hofe Reipach ${ }^{1}$ ) zu entrichten brauche. Hinsichtlich der Abbaltung des Gottesdienstes in Sistig traf er, nacbdem er von beiden Parteien zur Schlichtung der schwebenden Streitigkeiten angegangen war, die Bestimmung, dass das Kloster trotz der Aussage einzelner Leute, ihre Kapelle sei von alters her eine Pfarrkirche gewesen, doch nur einmal in der Woche, abgesehen vom Sonntage, die hl. Messe zu lesen die Pflicht habe, solange nicht durch Almosen seitens der Gläubigen in anderer Weise für den Gottesdienst gesorgt sei ${ }^{2}$ ).

Nachdem der Graf Conrad durch diese Anordnung in allen Punkten zugunsten des Klosters entschieden hatte, zeigte der Erzbischof Engelbert I. (1216-1225), welcher nach dem Rücktritt Adolfs I. den Kölner Stuhl bestiegen batte, dem Kloster im Anfange des Jahres 1219 sein besonderes Wohlwollen, indem er ihm die Übertragung des Patronatsrechts iiber die Kirche Mersburden seitens des Grafen Lothar von Hochstaden ${ }^{3}$ ) bestätigte und zugleich den Zehnten verlieh, den bis dahin der Pastor von Mersburden bezogen hatte. Als Grund für diesen Erweis seines Woblwollens bezeichnete er ausdrücklich den Zweck, dass das Kloster noch besser als früher in seiner bekannten freigebigen Weise die Gastfreundschaft üben könne ${ }^{4}$ ).

Da aber bisher keiner der rechtmässigen Pfarrer in eigener Person die kirchlichen Dienste in Mersburden verrichtet hatte, übertrug er, um diesem Übelstande abzuhelfen, dem Abte von Steinfeld das Recht, der Kirche einen geeigneten Priester als Pastor vorzusetzen, der persönlich die Seelsorge ausüben und dafür als Früchte beziehen sollte: 8 Schillinge und 11 Pfennige, 18 Malter Hafer, 2 Malter Weizen, 2 Malter Malz, den Ertrag aller

1) S. oben S. 64 . Boos a. a. O. 3. Heft, S. 52. Schannat-Bärsch a. a. O. 3. Bd. 1. Abt. 1. Abschn., S. 68.

2) S. Annalen 23, S. 160 f. Mitt. aus d. Stadtarchiv von Köln 3, S. 15.

3) S. oben S. 70 .

4) Über die Verwendung der Zehnteinkünfte zu charitativen Zwecken s. Schreiber a. a. O. I, S. $287 \mathrm{f}$. 
zur Kirche gebörigen Äcker, die Messpfennige (nummos missales, qui vulgo dicuntur Missanc) und alle Oblationen. Andererseits musste dej Pastor die Pflicht übernehmen, aus dem kleinen Zehnten (minuta decima) allen seinen Verpflichtungen gegen die Kirchenfabrik nachzukommen ${ }^{1}$ ), sowie das Kathedratikum an den Erzbischof und die Abgabe an den Archidiakon und den Dekan zu entrichten ${ }^{2}$ ).

Aus demselben Jahre (1219) teilt der Annalist Hugo weiter mit $^{3}$ ), dass der Papst Honorius III. auf Bitten des Erzbischofs Engelbert dem Steinfelder Kloster das Recht verliehen habe, zu allen ihm gehörigen Pfarrkirchen der Erzdiözese bei eingetretener Vakanz aus den Steinfelder Chorherren geeignete Personen zu präsentieren, welche die Einkünfte an den Abt zu entrichten bätten, damit dieser in noch umfangreicherem Masse als bisher die Werke der Gastfreundschaft üben könne. Eine direkte Bestätigung dieser Mitteilung ist zwar nirgendwo zu finden, aber ibre Richtigkeit kamn gleichwohl nicht bestritten werden, wie sich weiter unten ergibt ${ }^{4}$ ).

Auch der Nachfolger des Exzbischofis Engelbert, Heinrich I. von Molenark (1225-1238), zeigte sich dem Kloster sehr gewogen, als er unter vollständiger Wahrung der klösterlichen Interessen für eine geordnete Seelsorge der Bewohner von Schleiden Vorsorge traf. Da diese wegen ibrer weiten Entfernung von der Nutterkirche in Steinfeld, zumal im Winter, mit grossen Schwierigkeiten zu kämpfen hatten, um ihren religiösen Bedürfnissen und Pflichten zu genügen, erbaute der Edelherr Friedricb von Schleiden, ein Sobn jenes Grafen Conrad, welcher mit der Abtei in beftige Zehntstreitigkeiten geraten war ${ }^{5}$ ), in der Nähe seiner Burg mit Zustimmung des Steinfelder Abtes eine Kapelle, welche fortan von den in der Nachbarschaft wobnenden Leuten besucht werden konnte ${ }^{6}$.

1) Uber die Zehntverwendung zugunsten der Fabrik s. ebenda II; S. $86 \mathrm{ff}$.

2) S. Hugo, Probationes II, col. 528. Knipping a. a. O. IJI, S. 44.

3) S. Annales II, col. 855.

4) S. S. 95 Anm. 1. Amı 25. März 1220 erteilte der Papst Honorius 11 I. auch dem Stifte Knechtsteden dieselbe Befugnis, wenn auch nicht mit derselben Begründung. S. Ehlen, Die Prämonstratenserabtei Knechtsteden. Köln 1904. Urkundenbuch S. 21 f. Nr. XXIII.

5) S. oben S. 68 ff. 79 ff. Schannat-Bärsch a. a. O. 1. Bd. 2. Abt. S. 656 .

6) Die Steinfelder Kirche feierte später das Gedächtnis des Edelherrn Friedrich, der auch sonst dem Kloster sich wohlwollend exwies, 
In Anerkennung der bestehenden Notlage erteilte der Erzbischof Heinrich im Jahre 1230 auf Bitten des edlen Burgherrn und in Gegenwart der beiden Steinfelder Chorherren, der Pfarrer Albert von Ripsdorf und Petrus von Reifferscheid ${ }^{1}$ ), bereitwillig die Erlaubnis, dass die Kapelle mit dem zugehörigen Kirchbofe geweiht werde, behielt aber sämtliche Rechte, welche die Steinfelder Kirche bisher ausgeübt batte, das Recht, zu taufen, zu beerdigen, Beichte zu hören, den Send und iuberhaupt alle Pfarrrechte sowie den Neubruchzehnten im Pfarrbezirke dem Kloster vor und bestätigte sie von nevem ${ }^{2}$ ). Als der Abt Macarius mit dem Ritter Werner von Weisweiler über den Zehnten in dem Seelsorgebezirk Call in Streit geraten war, schloss er mit ihm am 12. September 1238 einen Vergleich, welcher den vollständigen Verzicht des Ritters anf alle seine Ansprïche zur Folge hatte. Um ihm aber an zeitlichen und geistlichen Gütern einen Ersatz zı schaffen, verpflichtete er sich, ibm jährlich am Feste Mariä Lichtmess zwei Kerzen ron einem und einem balben Pfund Wachs und am 1. Oktober vier Ellen Tuch zu einem Jagdanzuge und für die Jagdhunde ein Leitseil zu geben, sowie ihn und seine Frau in die Gebetsverbruidernng aufzunehmen und bei ibrem Tode eine gottesdienstliche Feier zu halten, wie sie für einen Klosterbruder iiblich war. Zugleich versprach er, um den Wünschen der Bewohner von Call entgegenzukommen, in der dem hl. Nikolaus daselbst geweihten Kapelle wöchentlich einmal die hl. Messe lesen $\mathrm{zu}$ lassen ${ }^{3}$ ).

Auch sonst sah sich Macarius öfters genötigt, die Rechte und Besitzungen des Klosters mit nachdrucksvoller Entschiedenheit gegen feindliche Angriffe zu verteidigen. So hatte in dem Orte Wehr im Kreise Mayen, welcher ganz dem Kloster Steinfeld gehörte $\left.{ }^{4}\right)$, Theoderich mit dem Beinamen Urso auf Grund des Erbrechts gewisse Güter für sich in Ansprnch genommen. Aber in der Auseinandersetzung, welche infolgedessen auf Veranlassung

am 15. Oktober: Item Friderici domini de Sleyda, qui dedit equum valentem LX marcas. S. Boos a. a. O. 3. Heft, S. 49.

1) S. Annalen 93, S. 20. 27.

2) S. die Urkunde im Schleidener Kopiar. saec. XV, f. 9 (Steinfe]d Akten 12 a; Düsseldorfer Staatsarchiv). Knipping a. a. O. III, S. 109.

3) S. Tille a a. O. I, S. 167.

4) S. Annalen 93, S. 48. 
des Abtes mit den Vertretern des Klosters stattfand, überzeugte er sich, dass seine Voraussetzungen falsch und unbegründet waren, und zögerte darum nicht, dies offen einzugestehen. Am 15. Juli 1242 erklärte er ansdrücklich, dass ihm an dem Hofe, den Äckern, Wäldern und Wiesen, überbaupt an dem gesamten Besitztum des Klosters nicht das geringste Recht zustehe, und entsagte folglich für sich und seine Erben allen seinen Ansprüchen. Zugleich leistete er mit seinem Verwandten Conrad, welcher von dem Grafen von Hochstaden, dem Vogte des Klosters, in Wehr gefangen genommen war, den Versprechungseid, dass sie keine Rache üben, vor Gericht keine Klage anstrengen und das Klostey nicht nur nicht belästigen, sondern fördern und unterstützen wollten, so oft sich eine Gelegenheit dazu biete. Sollte wider Erwarten der Fall eintreten, dass sie ilrem Versprechen dennoch untreu würden, so verfielen sie der Strafe der Exkommunikation, von welcher nur der Steinfelder Abt lossprechen konnte ${ }^{1}$ ).

Einige Jahre später machten der Propst der Peterskirche in Zülpich ${ }^{2}$ ), der Schenk Christian von Nideggen ${ }^{3}$ ) und mehrere Leute aus der Kölner, Lütticher und Trierer Diözese ungerechte Angriffe auf die Güter, welche das Kloster Steinfeld in Zülpich besass, wie Zehnten, Ländereien, Wiesen, Weingärten, Tiere und sonstige Besitzungen. Als der Abt Macarius sich deswegen beim Apostolischen stuble beschwerte, beauftragte Papst Innocenz IV. am 31. Oktober 1246 den Dechanten und Schatzmeister des $M$ ünstereifeler Stiftes, beide Parteien zusammenzuberufen, das Urteil zu fallen und die Vollstreckung desselben mit kirchlichen Strafmitteln durclizusetzen. Wenn die geladenen Zeugen aus irgend= einem Grunde, wie Gunst, Hass oder Furcht, die Aussage verweigern würden, sollte er sie ebenfalls durch Anwendung dieser Mittel zwingen, der Walırheit Zeugnis zu geben ${ }^{4}$ ).

1) S. die Originalurkunde Nr. 10 in Staatsarchiv zu Düsseldorf. Tille a. a O. I, S. 167 .

2) Die Propstei war von dem Erzbischof Friedrich I. im Jahre 1124 gestiftet und mit Benedilitinem aus der Abtei Siegburg besetzt worden. S. Broix a. a O. S. $82.212 \mathrm{ff}$.

3) Er ist das crste nachweisbare Glied der weitverzweigten Familie Schenk von Nidegg'en. S. (awonym) Geschichte der Familie Schenk von Nidegyen. Köln u. Neurs 18ti0, S. 29 f. u ud den Stammbaum im Anhang. 4) S. die Origmalurkunde Nr. 12 im Staatsarchiv zu Düsseldorf. 
So sebr Macarius durch die zablreichen grossen Aufgaben, welche $\mathrm{ihm}$ das Steinfelder Kloster steilte, in Anspruch genommen wurde, so hinderten sie ihn doch nicht, nach dem Beispiele seiner Vorgänger seine Sorge auch den Tochterklöstern zuzuwenden, indem er ihre Entwicklung väterlich woblwollend überwachte und seine Rechte mit Bestimmtheit in ihnen geltend machte. Von dem Stifte Strahow in Prag, welches ron dem ersten Propste Evervin gegriundet war $^{1}$ ), ist allerdings weiter nichts bekannt, als dass Macarius im Jahre 1240 bei Gelegenheit einer Visitation den Abt Petrus wegen schlechter Vermögensverwaltung absetzte ${ }^{2}$ ). Aber zahlreiche Urkunden geben Auskunft über seine Tätigkeit in den anderen Prämonstratenserklöstern, welche der Leitung des Steinfelder Mutterklosters unterstanden. So schlichtete er im Jahre 1217 eine Streitigkeit, welche zwischen dem Kloster Dünwald und dem Stifte St. Florin zu Koblenz ïber die Ausïbung des Patronatsrechts in der Kirche zu Obermendig im Kreise Mayen ausgebrochen war $^{3}$ ); in den Jahren 1220, 1231 und 1236 nahm er für das Kloster Dünwald Schenkungen entgegen und bestätigte und besiegelte die ausgefertigten Urkunden ${ }^{4}$ ).

Aus Gründen, die nicht näher bekannt sind (ex causis quibusdam), wurde das Kloster Dünwald in der Folge nicht nur der Leitung des Mutterklosters Steinfeld, sondern dem Prämonstratenserorden überhaupt vollständig entzogen ${ }^{5}$ ). Im Jahre 1244 versah

1) S. Anvalen 93 , S. 34 ff.

2) S. A. Frind, Die Kirchengeschichte Böhmens im allgemeinen und in ihrer besonderen Beziehung auf die jetzige Leitmeritzer Diözese. 2. Bd. Prag 1866, S. 192 f. Am 14. Juli desselben Jahres hielt Macarius sich nachweislich auf dem festen Bergschlosse Alttitschein im nordöstlichen Mähren auf, welches dem Grafen Arnold von Hückeswagen gehörte, um aus dessen Händen die oben S. 78 erwähnte Schenkungsurkunde entgegenzunehmen.

3) S. Mittelrheinisches Urkundenbuch III, S. $69 \mathrm{f}$. Zeitschr. des Berg. Geschichtsvereins 20. Bd., S. 64 f. Annalen 44, S. 46 f.

4) S. ebenda S. $70 \mathrm{f}$. Kremer a. a. O. III, S. $76 \mathrm{f}$. Zeitschr. des Berg. Geschichtsvereins 20, S. 67: Zwei dem Abte Macarius übergebene Schenkungen für das Kloster Meer, in welchem die Zahl der Schwestern durch Beschluss des Konventes und mit Gutheissung des Papstes Honorius III. vom 31. August 1217 auf 40 festgesetzt wurde, s. Lacomblet a. a. O. II, S. 22 Nr. 42 ; S. 35 Nr. 65 ; S. 83 Nr. 158.

5) S. Hugo, Probationes I, col. 541. Hoc eodem anno 1236 monasterium Dunwaldense ab ordine nostro Praemonstratensi avulsum erat. S. Annalen 44, S. 109. 
ein Benediktinermöncb aus der Abtei Brauweiler namens Gerhard, der als Kaplan dem Kloster vorübergehend zugewiesen war, dort den Gottesdienst ${ }^{1}$ ). Bis zum Ende des Jabres 1247 (25. Dezember) standen nicht, wie bisher, Prioren, sondern Pröpste dem Kloster vor (1236 Helyas, 1244 Arnold, 1247 Helyas) $^{2}$ ), so dass Macarius, da er im Laufe dieses Jahres starb, die Wiedervereinigung des Klosters mit Steinfeld und dem Prämonstratenserorden nicht melır erlebte.

In dem Tochterkloster Mariengarten in Friesland, welches unter dem zweiten Propste Ulrich gegründet war ${ }^{3}$ ), fand Macarius wiederholt Gelegenbeit, bei dem Tode des Vorstehers die Wahl des Nachfolgers zu leiten. Als der Abt Siard dort am 13. November 1230 das Zeitliche gesegnet hatte, erteilte er den Äbten Thidward von Dockum und Sigehard von Lidlum, einer Tochtergründung von Mariengarten, die nötigen Vollmachten und entsandte die beiden Steinfelder Chorherren Goslich und Reiner, um durch sie die von jenen vollzogene Wahl, aus welcher Sibrand hervorgegangen war, bestätigen zu lassen ${ }^{4}$ ). Acht Jahre später (1238), als auch dieser $A b t$ aus dem Leben schied, schickte er seinen Prior Peter zur Vornahme einer Neuwahl nach Mariengarten. Dieser berief die Äbte aus den benachbarten Prämonstratenserklöstern zu einer Beratung, in der er selbst den Vorsitz führte, and veranlasste sie zu einem Kompromiss, durch welchen der Chorberr Iaricus, der damalige Pastor in Grind, ein schon bejahrter und sittlich gereifter Mann, als Abt erkoren wurde ${ }^{5}$ ). Schliesslich aber fuhr Macarius, da durch die Abdankung dieses Abtes nochmals eine nene Besetzung des Amtes nötig wurde, im Beginn des Jahres 1242 selbst den Rhein herunter und kam mit den Äbten Allardus von Bern bei Heusden und Sigebodus von Lidlum um das Fest der heiligen Gertrud (17. März) nach Mariengarten. Sofort berief er die übrigen Personen, welche ordnungsgemäss zu

1) S. Mittelrheinisches Urkundenbuch III, S. 595 Nr. 793. Zeitschr. des Berg. Geschichtsvereins 20, S. 68.

2) S. Annalen 44, S. 72.108 f. Zeitschr. des Berg. Geschichtsvereins 20 , S. 68.

3) S. Annalen 94, S. $32 \mathrm{ff}$.

4) S. Hugo, Annales II, col. 855. Mon. Germ. hist. Script. XXIII, p. 576 .

5) S. ibid. p. 585 sq. 
der Wahl einzuladen waren, auf den 21. März zusammen und fiilurte trotz lebhaften Widerspruchs einzelner Wähler die Angelegenheit zu dem glücklichen Ende, dass mit grosser Majorität der Diakon und Kanonikus Ethelger gewäblt wurde, welcher friiher Notar und Kaplan des Abtes Sibrand gewesen war ${ }^{1}$ ).

$\mathrm{Zu}$ den Pflichten, welche Macarius seinen Tochterklöstern gegenüber ständig zu erfüllen hatte, kamen vorübergehend noch andere Aufgaben binzu, wenn bei besonderen Gelegenheiten sein Rat und seine Hilfe in anderen Prämonstratenserklöstern wünschenswert erschienen. So erbielt er im Jahre 1219 in Verbindung mit dem Abte Bruno von Rommersdorf und den Pröpsten Hermann von sayn ${ }^{2}$ ) und Johannes von Heinsberg ${ }^{3}$ ) von dem Erzbischof Engelbert den Auftrag, eine Untersuchung über eine Streitigkeit vorzunehmen, welche zwischen dem Abte des Prämonstratenserklosters Hamborn und der Meisterin des ihm unterstehenden Prämonstratenserinnenkloster's Füssenich ${ }^{4}$ ) bei Zülpich einerseits und einzelnen Schwestern des Klosters und fast sämtlichen Laienbrïdern in Füssenich andererseits ausgebrochen war ${ }^{5}$ ).

Ungefähr um dieselbe Zeit ${ }^{6}$ ) wandte er sich brieflich an den Abt Gervasius in Prémontré, um eine Angelegenheit zu regeln, welche seinen Freund und Ordensbruder betraf, den eben genannten Propst Johann von Heinsberg. Da dieser eine sehr aszetisch veranlagte Natur war und mit Vorliebe die ewigen und ernsten Wabrheiten

1) S. ibid. p. $587 \mathrm{sqq}$.

2) Die im Jahre 1204 beschlossene Erhebung der Propstei Sayn zur Abtei (s. oben S. 71) scheint später wieder rückgängig gemacht worden zu sein. Während der Papst Innocenz III. am 4. Mai 1208 eine Urkunde an den Abt Hermann richtete, traten in Urkunden aus den Jahren 1219-1228 als Klostervorsteher die Pröpste Hermann und Ludolf auf. Erst vom Jahre 1229 ab ist wieder ein Abt nachweisbar. S. Mittelrheinisches Urkundenbuch II, S. $272 \mathrm{Nr} .234$; III, S. $112 \mathrm{Nr} .117$; S. 130 Nr. 143 ; S. 131 Nr. 144 ; S. 157 Nr. 181; S. 227 Nr. 280 ; S. 267 Nr. 332 ; S. 284 Nr. 353 ; S. 291 Nr. 363.

3) S. F. Kreetz, Historia nobilis Parthenonis Heinsbergensis. Coloniae Agrippinae 1772, p. 220.

4) S. Fabricius a. a. O. S. 236 . Knipping a. a. O. II, S. 77 Nr. 456.

5) S. Hugo, Sacrae antiquitatis mouumenta I, p. 109 sq. Knipping a. a. O. III, S. $47 \mathrm{Nr}$. 245.

6) Da Gervasius bis zum Jahre 1220 Abt war, kann nur die Zeit von 1211; vom Regierungsantritt des Abtes Macarius in Steinfeld, bis 1220 in Frage kommen. S. Eubel l. c. p. 427. 
der Religion betrachtete, glaubte er, dass er durch die Ausübung der Seelsorge und der Verwaltung zu sehr von seinem eigentlichen Ziele, der persönlichen Heiligung, abgelenkt werde, und bat darum den Generalabt inständig, ihn von seinem Amte zu entbinden. Um seiner Bitte mehr Nachdruck zu geben, liess er zugleich durch den Steinfelder Abt in demselben Sinne nach Prémontré berichten.

Auf dieses Schreiben erhielt Macarius die Antwort, er solle, wenn möglich, einige von seinen Steinfelder Ordensbrüdern nach Heinsberg schicken, damit sie den Propst in der Ausübung seines Amtes unterstützten und dazu beitrügen, dass der Heinsberger Konvent in Blüte komme und eine Zierde des Ordens werde; wenn er aber dazu nicht in der Lage sei, so solle er in seinem Auftrage den Propst seines Amtes entsetzen; es sei doch besser, dass er ganz zuriucktrete, als unnütz seine Tage im Vorsteheramte zuzubringen und sich selbst in seinem Streben nach Vollkommenheit im Wege zu stehen. Zugleich erhielt Macarius über das Heinsberger Kloster, da es wegen seiner weiten Entfernung der Beaufsichtigung seitens des Abtes von Prémontré entrückt war, das Visitationsrecht mit der Verpflichtung, häufig von demselben Gebrauch zu machen und alle Vorkehrungen zu treffen, welche für eine gedeihliche klösterliche Entwicklung notwendig waren ${ }^{1}$ ).

Gegen das Ende seines Lebens wurde Macarius auf Grund einer päpstlichen Urkunde mit einer neuen Aufgabe betrant, welche als dauernd beabsichtigt war und zahlreiche neue Pflichten im Gefolge gehabt haben würde, wenn sie in der Tat von Daver gewesen wäre. Denn am 22. April 1246 stellte Innocenz IV. das Prämonstratenserinnenkloster de Pace Dei zu Blankenberg a. d. Sieg auf den Wunsch der Äbtissin und des ganzen Konventes unter die Leitung des Abtes von Steinfeld und beauftragte ibn-nnter Wahrung aller Rechte des Kölner Erzbischofs --, zur geeigneten Zeit dasselbe entweder persönlich zu visitieren oder durch einige seiner Ordensbrüder visitieren zu lassen. Diese erhielten zugleich die Vollmacht, die Schwestern in der klösterlichen Zucht zu unterweisen, ibre Beichten zu hören und ihnen die übrigen Sakramente zu spenden ${ }^{2}$ ).

1) S. Hugo, Sacrae antiquitatis monumenta l. c. p. 58.

2) S. die Originalurkunde mit anhangendem Bleisiegel im Staatsarchiv zu Düsseldorf. 
Aber dieses Kloster de Pace Dei, welches von der Gräfin Mechtilde, der Gemahlin Heinrichs von Sayn, gegründet war, blieb binsichtlich seiner geistlichen Leitung nur ein Jahr und sieben Monate in der Abbängigkeit von dem Steinfelder Abte. Da der Graf Heinrich, welcher am 1. Januar 1247 aus dem Leben geschieden war $^{1}$ ), letztwillig verfügt hatte, dass aus seinen Gütern zwei Klöster für Zisterzienserinnen erbaut und ausgestattet würden, richtete die Witwe Mechtilde später aus Gewissensbedenken, sie möchte wegen der Errichtung des Prämonstratenserinnenklosters ${ }^{2}$ ) zu Blankenberg gegen die ausdrückliche testamentarische Bestimmung ihres Gatten gehandelt haben, an den Papst Innocenz die Bitte, ihr die nötigen Anweisungen zu geben, wie sie die beabsichtigte Stiftung in rechter Weise ausführen könnte.

Nachdem der Papst den Kardinaldiakon Petrus von St. Georg, welcher am 15. März 1247 als Legat nach Deutschland gesandt $w^{3}{ }^{3}$ ), mit der Erledigung der Angelegenheit betraut hatte, verordnete dieser kraft apostolischer Vollmacht am 30. November desselben Jahres, dass das Kloster dem Zisterzienserorden inkorporiert und der Leitung des Abtes Gerhard von Heisterbach unterstellt werde. Dieser erhielt zugleich den Auftrag, persönlich die Nonnen in Blankenberg in den Satzungen des Zisterzienserordens zu unterweisen, sie regelmässig zu passender Zeit zu visitieren und etwaige Fehler und Missbräuche bei ibnen abzustellen ${ }^{4}$ ).

Wenn durch die Entscheidung des Kardinaldiakons der Steinfelder Abt seiner Rechte und Pflichten in bezug anf das Kloster zu Blankenberg wieder enthoben wurde, so erhielt er

1) S. Becker a. a. O. S. 280.

2) In der Urkunde ist die Rede von der ecclesia de Pace Dei in Blankenberg ordinis s. Augustini. Dass diese ecclesia aber aus Prämonstratensernonnen gebildet wurde, ergibt sich aus den Worten der eben erwähnten Urkunde des Papstes Innocenz IV. vom Jahre 1246: Dilectae [in Christo filiae abbatissa et conventus monialium de Pace Dei Praemonstratensis ordinis.

3) S. Böhmer a. a. O. S. 1549 . Eubel l. c. p. 7. 50.

4) S. Lacomblet a. a. O. II, S. $167 \mathrm{Nr}$. 321. Böhmer a. a. O. S. 1551 Nr. 10 203. Urkundliche Nachrichten über das Zisterzienserinnenkloster de Pace aus den Jahren 1248 und 1252 s. Lacomblet a. a. O. II, S. 177 Nr. 340 ; S. $178 \mathrm{Nr} .341$; S. 202 Nr. 379 . Knipping a. a. O. III, S. 202 Nr. 1433. 1434; S. 228 Nr. 1657. 
andererseits gewisse rechtliche Befugnisse über das Nonnenkloster Niederehe im Kreise Daun, dessen Mitgliederzahl sich gemäss einer Bestimmung des Erzbischofs Engelbert vom Jahre 1218 auf höchstens 25 belaufen sollte ${ }^{1}$ ). Als der Pfarrverweser Otto von Lommersdorf ${ }^{2}$ ) diesem Kloster im Jahre 1226 eine Rente von $4^{1 / 2} \mathrm{Obm} W_{e i n}^{3}$ ) zu dem Zwecke schenkte, vom ersten Fastensonntage ab wöchentlich dreimal, am Sonntag, Dienstag und Donnerstag, die ganze Fastenzeit hindurch allen Mitgliedern des Konventes einen Becher darzureichen, ferner bei ausreichender Quantität auch an den Tagen des Osterfestes, verbot der Erzbisehof Heinrich urkundlich jede absichtliche Ungehung dieses Zweckes und wies den Abt von Steinfeld an, falls eine dem Kloster angehörige Person sich dennoch dazu versteige, diese aus der kirchlichen Gemeinschaft auszuschliessen ${ }^{4}$ ).

Bevor Macarius aus dem Leben schied, ging die Vogtei über das Kloster Steinfeld, welche im Jahre 1205 mit dem Besitze 'des Schlosses Are in die Hände des Grafen von Hochstaden ge-

1) S. Mittelrheinisches Urkundenbuch III, S. 88 Nr. 90. Knipping a. a. O. III, S. $42 \mathrm{Nr}$. 224. Die ausgefertigte Urkunde unterschrieb Macarius als Zeuge. Andere Urkunden, in denen er als Zeuge fungierte, s. bei Hugo, Annales II, col. 855. Lacomblet a. a. O. II, S. 39 Nr. 71; S. 102 Nr. 194.

2) S. Schannat-Bärsch a. a. 0. 3. Bd. 1. Abt. 1. Abschn. S. 107 f. Fabricius a. a. O. S. 164.

3) Dass bei den für die Stifter und Klöster festgesetzten Lieferungen die carrata $=41 / 2 \mathrm{Ohm}$ war, $\mathrm{s}$. L. Ennen, Geschichte der Stadt Köln. 1. Bd. Köln u. Neuss 1863, S. 505.

4) S. Mittelrheinisches Urkundenbuch III, S. 243 Nr. 303. Knipping a. a. O. III, S. $92 \mathrm{Nr}$. 593. Es liegt die Vermutung nahe, dass die, ursprünglichen Augustinernonnen des Klosters Niederebe, welche im Jahre 1244 nachweislich Angehörige des Prämonstratenserordens waren, im Jahre 1226 die Umwandlung bereis vollzogen hatten. Denn in diesem Jahre wurden sie von einem Prior geleitet, während gemäss den Anweisungen der Erzbischöfe Philipp und Adolf (c. 1175 und 1197) ein religiosus provisor, qui sit de regula Augustini an der Spitze stehen sollte; ferner treten in der erzbischöflichen Urkunde von 1226 als Zeugen (abgesehen von den Vertretern des Klosters) n u r Angehörige des Prämonstratenserordens auf, nämlich ausser dem Abte Macarius auch sein Prior Hermann und sein Kellermeister Gerhard sowie die beiden Prämonstratenserpfarrer Albert von Ripsdorf und Anselm von Berndorf. S. Mittelrheinisches Urkundenbuch IIJ, S. 604 Nr. 806 . Knipping a. a. 0. III, S. $170 \mathrm{Nr}$. 1162. Annalen 23, S. $155 \mathrm{f}$. 
kommen war ${ }^{1}$ ), weiter an die Erzbischöfe von Köln über, da der Graf Friedrich von Hochstaden, Propst von St. Maria ad gradus in Köln, am 16. April 1246 mit der Grafschaft Hochstaden auch das Schloss Are bei Altenahr dem erzbischöflichen Stuhle zu Händen des zeitigen Inhabers, seines Bruders Conrad, übertrug ${ }^{2}$ ). Macarius starb im Anfange des Jahre 1247 im hohen Alter, nachdem er 36 Jahre der Abtei mit Umsicht und Tatkraft vorgestanden hatte ${ }^{3}$ ).

\section{Die Abtei Steinfeld um die Mitte des 13. Jahrhunderts. Die Aebte Gerhard, Goswin und Lambert (1247-1258).}

Nach dem Hingange des Abtes Macarius folgten drei Vorsteler, die zu kurze Zeit den Abtstab führten, als dass sie einen nachhaltigen Einfluss auf die innere und äussere Entwicklung der Abtei hätten ausüben können.

\section{Abt Gerhard (1247-1248).}

Gerhard, der erste von ihnen, welcher sein Amt in der Fastenzeit des Jahres 1247 antrat, war aus dem Steinfelder Konvente hervorgegangen. Im Jahre 1226 hatte er in demselben das Amt des Kellermeisters ausgeübt ${ }^{4}$ ) und im Jahre 1240 seinen Abt Macarius nach der Burg Alttitschein in Mähren begleitet, um als Zeuge dem Schenkungsakte des Grafen Arnold von Hückeswagen beizuwohnen ${ }^{5}$ ). Am 18. Dezember 1247 schloss er in Gegenwart seiner geistlichen Ordensbrïder, des Priors Lambert und des Kellermeisters Ludwig sowie des Laienbruders Wolbero, des Hofmeisters Adam in Geroldshoven und des Hofmeisters Winand in Heimers-

1) S. oben S. 69.

2) S. Lacomblet a. a. O. II, S. 155 Nr. 297 . Cardauns a. a. O. S. 57 ff. Die Übertragung wurde am 26. Juni 1246 vom Papste Innocenz IV. bestätigt. S. Knipping a. a. O. III, S. 182 Nr. 1266.

3) Die Abtei Arnstein feierte das Gedächtnis des Abtes Macarius am 31. August, das Stift Heinsberg am 18. und die Abtei Rommersdorf am 19. September. S. Becker a. a. O. S. 159. Zeitschr. des Aachener Geschichtsvereins 1, S. 274 . Wegeler a. a. 0. S. 98.

4) S. oben S. 90 .

5) S. oben S. 78 und 85. Ob dieser Abt Gerhard identisch ist mit einem der beiden gleichnamigen Chorherren, von welchen der eine um 
heim ${ }^{1}$ ) einen Vergleich mit dem Ritter Beinrich von Attenbach (bei Blankenberg a. d. Sieg), welcher für seine dem Kloster verpachteten Ländereien im Umfange von $4 \frac{1}{2}$ Morgen die in der Volkssprache "Niederfall und Aufkommen" genannten Abgaben beanspruchte (obventiones, quae vulgari vocabulo niderval et upcuminge dicuntur), die ihm beim Tode des Abtes Macarius hätten entrichtet werden müssen ${ }^{2}$ ). Da das Kloster dem Ritter Heinrich bisher von diesen Ländereien jährlich 5 Malter Weizen oder 4 Malter Hafer geliefert hatte, je nachdem Weizen oder Hafer gesät war, und in jedem dritten Jahre, wenn man den Acker nicht zu bestellen pflegte, von einer Abgabe frei geblieben war, einigten beide Parteien sich dahin, dass das Kloster in Zukunft als Ersatz für die beanspruchten Abgaben das erhöhte Mass von 6 Maltern Weizen bzw. 5 Maltern Hafer als Abgabe zu zahlen hatte und in jedem dritten Jahre, wie bisher, frei blieb. Ausserdem übernahm das Kloster die Verpflichtung, wegen eines hinter Geroldsberg gelegenen Stückes Neubruchsland, welches es ebenfalls von dem Ritter Heinrich gepachtet batte, einen jäbrlichen Zins von 6 Kölner Denaren zu zahlen. Sowohl die Rente als auch der Zins waren jährlich am Feste des hl. Remigius (1. Oktober) von dem Hofe des Klosters in Geroldshoven zu entrichten ${ }^{3}$ ). Nachdem diese Streitsache auf gütlichem Wege erledigt war, bemühte sich Gerhard, auch eine andere strittige Angelegenbeit, in welcher es sich um Grundbesitz handelte, in derselben Weise ins reine $\mathrm{zu}$ bringen. Der Pastor Hermann von Roitzheim im Kreise Rheinbach und fünf seiner Verwandten belangten das Kloster wegen 30 Morgen Ackerland und zwei Hofstätten, welche zu dem Hofe Königsfeld ${ }^{4}$ ) bei Dottel im Kreise Schleiden ge1202 Prior in Dünwald (Annalen 44, S. 108) und der andere in den Jahren 1196-1207 Prior in Meer war (Keussen a. a. O. S. 52), ist wohl schwerlich festzustellen, aber immerhin möglich. Im letzteren Falle würde Gerhard erst in sehr hohem Alter in Steinfeld Abt geworden und so sein baldiger Tod vom natürlichen Standpunkte aus leicht zu erklären sein.

1) Uber die Besitzungen des Klosters in Geroldshoven bei Ahrweiler s. Annalen 93, S. 30 und oben S. 79, in Heimersheim s. oben S. 66.

2) Uber diese Abgaben s. Annalen 28, S. 20.

3) S. Mittelrheinisches Urkundenbuch III, S. $692 \mathrm{Nr}$. 922. Mitt. a. d. Stadtarchiv 3, S. 30.

4) S. G. Bärsch, Das Prämonstratenser-Mönchskloster Steinfeld in der Eifel. Schleiden 1857, S. 11. 
hörten, während der Abt auf dem Landkapitel in Zülpich vor dem Kanonikus und Magister Heinrich von St. Maria ad gradus in Köln, dem Stellvertreter des Propstes dieses Stiftes, Friedrich von Hochstaden, welcher in dem Dekanate Zülpich die Rechte des Landdekans ausübte ${ }^{1}$ ), diese Güter auf Grund des Erbrechts für das Kloster in Anspruch nahm.

Nachdem die beteiligten Personen darüber einig geworden waren, den gerichtlichen Klageweg in diesem Falle nicht zu beschreiten, beauftragten sie den Pastor Hermann, ihnen einen Vergleich vorzuschlagen, und gaben die Erklärung ab, dass sie mit demselben unter allen Umständen einverstanden sein würden. Infolgedessen begab sich der Pastor an dem festgesetzten Termine nach Steinfeld und schloss nach eingehender Verhandlung mit dem Abte, der grosses Entgegenkommen zeigte, den ersehnten Frieden. Dieses gewonnene Resultat wurde von dem Kölner Kanonikus Heinrich auf einer neuen Kapitelssitzung in Zülpich am 10. März 1248 verkündet und urkundlich festgelegt, indessen ohne Angabe, wie und unter welchen Bedingungen es erzielt wurde ${ }^{2}$ ). Nicht lange nach diesem Ereignis wurde der Abt Gerhard aus dem Leben abberufen, nachdem er erst ein Jahr die Leitung des Klosters in Händen gehabt hatte.

$$
\text { 6. Abt Goswin I. (1248-1252). }
$$

Der Nachfolger Gerhards, Goswin I. von Jülich, welcher ebenfalls vor seiner Wahl zum Abte Mitglied des Steinfelder Konvents gewesen war $^{3}$ ), trat die Regierung (1248) zu einer Zeit an, wo die Abtei in Schulden geraten war. Denn die series praep. et abb. Steinf. meldet: Eius tempore vitis Steinfeldensis aliqualiter sterilis facta erat, non quod fructum bonorum operum non faceret, sed quod in temporalibus deficeret, ut fere dici potuerit illud Jerem. 8: Non est uva in vitibus. Ecclesia enim pluribus debitis erat obnoxia. Diese Schulden waren der Abtei dadurch erwachsen, dass sie für die Kriege des Erzbischofs Conrad ${ }^{4}$ ) ungewöhnlich

1) Diese Rechte hatte Erzbischof Anno II. durch Urkunde vom 29. Juli 1075 dem Propste des Stiftes Maria ad gradus übertragen. S. Lacomblet a. a. O. I, S. $143 \mathrm{Nr} .220$. Fabricius a. a. O. S. $212 \mathrm{f}$.

2) S. Annalen 23, S. 164 f. Mitt. a. d. Stadtarchiv 3, S. 30.

3) S. oben S. 78.

4) S. Ennen a. a. O. 2. Bd., S. 79 f. 82 f. 87 ff. 90 f. 94 . Cardauns a. a. O. S. 9 f. 69 ff. 
grosse Aufwendungen hatte machen müssen. Sagte doch der Erzbischof später in einer an den Abt und Konvent von Steinfeld gerichteten Urkunde vom Jahre 1260 selbst: Vobis [tamen] ad hoc existimus eo amplius debitores, quo nostris diebus circa vestra possessiones et bona nostrarum occasione guerrarum .. . graviora noscimini dispendia pertulisse ${ }^{1}$ ).

Unter diesen Umständen musste dem Kloster eine Schenkung sehr willkommen sein, welche der Graf Philipp II., Herr von Wildenburg, im Jahre 1250 machte, indem er ibm zum Seelenheil seines Dienstmannen von Birunge, welcher kürzlich an Altersschwäche gestorben war, eine Rente von 1 Malter Hafer stiftete ${ }^{2}$ ), sowie eine zweite Schenkung des Ritters Conrad von Schussenried, welcher mit seiner Gemablin Aleidis dem Kloster im folgenden Jabre (1251) von seinem Gute 6 Morgen Ackerland übertrug, die an den Hof des Klosters in Lückerath im Kreise Schleiden, genannt Münchhof, angrenzten ${ }^{3}$ ). Zum Ausdruck des Dankes für die gemachte Schenkung nahm der Abt Goswin am 1. August 1251 den Geschenkgeber mit seiner Gemablin und seinen Kindern in die Gebetsverbrüderung anf und sicherte ibnen nach ihrem Tode ein Begräbnis in dem Steinfelder Kloster mit einer feierlichen Messe de requiem $\mathrm{zu}^{4}$ ). Um aber dem Kloster die Möglichkeit zu verschaffen, die Schulden durch Erschliessung einer neuen ständigen Einnahmequelle zu decken, vereinigte der Erzbischof Conrad in seinem Bestreben, der Not der Stifter und Klöster durch Inkorporation von Pfarreien zu Hilfe zu kommen ${ }^{5}$ ), am 15. Oktober 1251 die Kirehe von Keldenich ${ }^{6}$ ) im Kreise Schleiden, über welche er in seiner Eigenschaft als Graf von Hochstaden das Präsentationsrecht besass, unter dem Vorbehalte der Kathedralstener und der Rechte des Archidiakons, mit der

1) S. Annalen 66, S. $191 \mathrm{f}$.

2) S. Schannat-Bärsch a. a. 0. 1. Bd. 2. Abt. S. 689.

3) S. Boos a. a. O. 3. Heft, S. 54 f. Schannat-Bärsch a. a. O. 3. Bd. 1. Abt. 1. Abschn., S. 65. 3. Bd. 2. Abt. 2. Abschn, S. 348. Vgl. oben S. 64.

4) S. die Originalurkunde Nr. 13 im Staatsarchiv zu Düsseldorf.

5) S. Cardauns a. a. O. S. $121 \mathrm{ff}$. Dass er klösterlichen Anstalten gegenüber im allgemeinen wenig freigebig war und ihnen gewöhnlich nur dann Wohltaten spendete, wenn sie ihn persönlich keine Opfer kosteten, s. ebenda S. $119 \mathrm{f}$.

6) S. Fabricius a. a. O. S. 163. 
Kirche von Steinfeld, so dass der Abt nach dem Tode des zeitigen Pastors auf Grund eines päpstlichen Privilegs ${ }^{1}$ ) je nach Bedürfnis durch einen oder mehrere seiner Ordensbrüder den gesamten Pfarrgottesdienst in der Kirche ausüben lassen konnte ${ }^{2}$ ).

Weitere Nachrichten iiber die Regierungstätigkeit des Abtes Goswin sind nicht erhalteu. Die in dem Chronodistichon der series praep. et abb. Steinf.:

RVrsVs VenIt eo sVb praesVle fILIa DVnVVaLt

NatIVa In SteInfeLt, seD pater abbas abIt. 1252.

angedeutete und irrtümlich der Regierungszeit Goswins zugewiesene Wiedervereinigung der Nonnen in Dünwald mit dem Kloster Steinfeld fällt wahrscheinlich in das Jahr $1257^{3}$ ).

\section{Abt Lambert (1252-1258).}

Nachdem Goswin in Jahre 1252 das Zeitliche gesegnet hatte, trat an seine Stelle der Abt Lambert, welcher früher unter dem Abte Gerhard das Amt des Priors versehen hatte ${ }^{4}$ ). Kurze Zeit nach seinem Regierungsantritte fübrte er einen Vergleich uiber Zehntstreitigkeiten berbei, welche seit geraumer Zeit zwischen

1) Worin dieses Privileg im einzelnen bestand, hatte der Erzbischof bereits in einem an die Archidiakone der Erzdiözese, gerichteten Schreiben vom 4. Juli 1246 mit den Worten bekanntgegeben: Cum de gratia sedis apostolicae abbatibus et capitulis praemonstratensis ordinis canonicos sui ordinis ad ecclesias praesentare, quarum ius patronatus ad ipsos dinoscitur pertinere, et canonicos sui ordinis praesentatos ab ipsis curam animarum, custodiam reliquiarum et investituram ecclesiarum recipere ac in eisdem ecclesiis personaliter liceat deservire ita quod dioecesano archidiacono et decano loci obedientiam et jura eis debita exhibere teneantur, nos speciali zelo pietatis moti etc. Sodann wies der Erzbischof die Archidiakone an, in den Patronatskirchen des Klosters Meer bei eingetretener Vakanz immer genau nach den Bestimmungen dieses Privileg's zu verfahren und demgemäss die präsentierten Chorherren zuzulassen und zu investieren. S. Kopiar saec. XVII B.93af. 58 b (Düsseldorfer Staatsarchiv). S. Knipping a. a. O. III, S. 182 Nr. 1270. Vgl, oben S. 82 .

2) S. Annalen 23, S. 168 f. Mitt. a. d. Stadtarchiv 3, S. 33. Knipping a. a. O. IIr, S. $228 \mathrm{Nr} .1648$.

3) S. unten S. 99. Die Abtei Rommersdorf feierte Goswins Gedächtnis am 23. November. S. Wegeler a. a. O. S. 100.

4) S. oben S. 91 . 
der Abtei und dem Herrn Friedrich von Schleiden ${ }^{1}$ ) ausgebrochen waren. Die Abtei forderte von allen Leuten des Edelherrn auf Grund ibrer Zugebörigkeit zur Pfarre Steinfeld den kleinen Ticrzehnten, wälrend die Vasallen und Ministerialen desselben die Rechtmässigkeit dieser Forderung mit dem Hinweis darauf bestritten, dass der Zehnte von ihren Vorfahren niemals entrichtet worden sei. Nachdem beide Parteien ïbereingekommen waren, die Entscheidung dem Urteile von Schiedsrichtern zu nnterwerfen, erkannten die mit diesem Amte betrauten Ordensmänner, die $\mathrm{D}_{0}$ minikaner Albero Schalle und Theodorich von Koblenz im Auftrage Friedrichs, der Prämonstratenser Heinrich, Prior und Kustos in Steinfeld, und der Pastor Johannes von Mersburden im Namen des Abtes Lambert, nach sorgfältiger Untersuchung folgendermassen: der Herr von Sehleiden und seine Erben brauchten von allen ihren Tieren, die sie auf ibren eigenen Höfen hielten, nicht den Zehnten zu zahlen, ebensowenig wie die Vasallen und Ministerialen, welche ihre Tiere auf den zu der Herrschaft Schleiden gehörigen Gütern mästeten. Hingegen waren zur Entrichtung des Zebnten verpflichtet: 1. die auf den Hö̈en des Herru von Schleiden wohnenden Leute, welche eigene Tiere hielten; 2. die Vasallen, Ministerialen und alle anderen, welche ibre Tiere den Lehnguitern irgendeines anderen zur Mast übergaben; 3. die Vasallen, Burgmannen und Ministerialen, welche ihre Tiere ausserbalb ibrer von der Herrschaft Scbleiden empfangenen Lehngüter unterbrachten; 4. Schäfer oder andere Leute, welche auf den Lehngütern der Vasallen oder Ministerialen eigene Tiere unterbielten oder mit ihnen eine Vermischung vornahmen; 5. alle übrigen Landleute, gleichviel auf welchen Gütern sie ihre Tiere grosszogen.

Entstand bezüglich der untereinander vermischten Tiere ein Zweifel darüber, wem sie ganz oder zum Teil gehörten, so sollte der Vasall oder Ministeriale, wofern der Zweifel nicht durch ein zuverlässiges Urteil gehoben werden konnte, durch eine eidliche Aussage die Sache klarstellen. Wurde von seiten des Herrn von Schleiden und seiner Leute oder auch von seiten des Abtes und des Klosters irgendeine der getroffenen Bestimmungen umgangen, so hatte der Teil, welcher glaubte, dass ihm Unrecht gescheben

1) Er war ein Sohn des oben (S. 82) erwähnten Edelherrn Friedrich von Schleiden. S. Schannat-Bärsch a. a. O. 1. Bd. 2. Abt., S. $656 \mathrm{f}$. 
sei, das Recht, den anderen Teil vor sich zu laden und den seines Curechts Überführten zum Schadenersatz aufufordern. Falls der tht innerhalb eines Monats, nachdem der Herr von Schleiden oder sein Bevollmächtigter die Aufforderung hatte ergehen lassen, derselben nicht nachkam und infolgedessen dem Herrn von Schleiden besondere Mühen und Auslagen erwuchsen, so wurde er nach vernünftiger Abschätzung ehrenwerter Männer zum Schadenersatz gezwungen. War der Herr von Schleiden überführt und aufgefordert, so musste er innerhalb drei Monaten den Schaden wieder gutmachen, widrigenfalls er exkommuniziert wurde.

Ferner hatte er die Pflicht, nach vorangegangener Aufforderung seitens des Abtes oder dessen Bevollmächtigten seine Leute im Übertretungsfalle wieder zu ordnungsmässigem Handeln anzuhalten. Blieben seine Bemühungen erfolglos, so verfielen die Schuldigen, wofern sie sich im Lande aufhielten, nacb Verlauf eines Monats der Exkommunikation. Mit derselben Strafe wurden die Vormünder der Minderjährigen und die Verwalter derjenigen belegt, welche in der Fremde weilten, wenn sie die Vereinbarung nicht beobachteten.

Sodann kam noch die Bestimmung hinzu, dass vom Heu der Zehnte nicht entrichtet zu werden brauchte, wohl aber von Erbsen, Wicken, Flachs und allen anderen Erzeugnissen, die auf den Äckern gewonnen wurden. Waren die Produkte ausnahmsweise in Gemüsegärten gezogen, so blieben sie steuerfrei, da solche Gärten gewöhnlich der Steuer nicht unterlagen.

Die über den geschlossenen Vergleich ausgestellte Urkunde, in welcher die genannten Schiedsrichter als Zeugen fungierten, wurde durch das Siegel des Erzbischofs Conrad, der hier zum ersten Male als Vogt der Abtei Steinfeld auftrat ${ }^{1}$ ), sowie durch die Siegel des Abtes Lambert und des Edelherrn Friedrich, die als Zeugen zugegen waren, bekräftigt ${ }^{2}$ ).

Am 12. März 1255 erhielt die Abtei eine namhafte Schenkung durch Heinrich von Reifferscheid, welcher ihr mit Zustimmung seiner Gemahlin Agnes seine sämtlichen in Bachem ${ }^{3}$ ) bei Ahrweiler

1) S. oben S. $90 \mathrm{f}$.

2) S. Annalen 23, S. 169 ff. Mitt. a. d. Stadtarchiv 3, S. 33. Knipping a. a. O. III, S. $235 \mathrm{Nr} .1713$.

3) Über die Güter, welche die Abtei in Bachem bereits besass, s. oben S. 64 . 
gelegenen Güter, bestehend in Renten, Weingärten, Äckern, Wiesen und Wäldern, testamentarisch unter der Bedingung ver. machte, dass er ohne Kinder sterben werde. Sollte sich nach seinem Tode herausstellen, dass noch irgend jemand eine kleine Schuld von ihm einzufordern berechtigt war, so musste die Abtei sie bezahlen, aber böchstens bis zu einem Betrage von 30 Mark. Ferner war sie verpflichtet, sofern er nicht in der Fremde starb, seinen Leichnam nach Steinfeld zu bringen und in dem Oratorium des Klosters beizusetzen, regelmässig für ihn das Jahrgedächtnis zu halten und den Brüdern im Refektorium am Gedächtnistage eine besondere Beköstigung zu gewähren. Falls ibm aber noch Kinder geboren wurden, welche die genannten Güter für sich behalten wollten, hatten diese an das Kloster zu Steinfeld 100 Mark zur Stiftung seines Jahrgedächtnisses zu entrichten ${ }^{1}$ ). Da der Geschenkgeber kinderlos starb, blieb das Testament rechtskräftig und erhielt durch Johann von Reifferscheid, den Sohn seines Bruders, den er $z u$ seinem Universalerben eingesetzt hatte, an 23. April 1282 eine urkundliche Bestätigung mit der Zusicherung, dass er das Kloster im Besitze und Genusse der erworbenen Gäter schützen werde ${ }^{2}$ ).

Gegen Ende desselben Jahres (2. Dezember 1255) verbot der Erzbischof Conrad seinem Truchsess von Hard ${ }^{3}$ ), von den Leuten des Klosters Steinfeld, welche sich in der Gegend von Marmagen aufhielten, irgendwelche (Mai- oder Herbst-) Bede ${ }^{4}$ ) zu fordern, da dieselben wegen ihrer andauernden, dem Erzbischöflichen Stuhle geleisteten Dienste eine völlige Abgabefreiheit verdienten ${ }^{5}$.

1) S. Annalen 23, S. 171 f. Mitt. a. d. Stadtarchiv 3, S. 37.

2) S. die Orginalurkunde Nr. 21 im Staatsarchiv zu Düsseldorf. Schannat-Bärsch a. a. 0. 1. Bd. 2. Abt., S. $621 \mathrm{f}$.

3) $\mathrm{Ob}$ der Truchsess Adam von Hart, welcher in zwei für das Kloster Steinfeld ausgestellten Urkunden aus den Jahren 1267 und 1269 auftritt, mit dem obengenannten Truchsess identisch ist, muss dahingestellt bleiben. S. Annalen 23, S. $176 \mathrm{ff} .180$.

4) S. Annalen 28 , S. 20.

5) S. Kopiar saec. XVIII. Nationalbibliothek in Paris, Fonds latin Nr. 17791 f. 53. Knipping a. a. O. III, S. 254 Nr. 1871. Ein Beamter der Nationalbibliothek (H. Omor? Unterschrift unleserlich) hatte die Güte, mir eine Kopie der kurzen, nur 54 Worte zählenden Urkunde zuzusenden. 
So erfreulich alle diese Gunsterweise, welche dem Kloster in materieller Hinsicht zuteil wurden, für den Abt Lambert sein mussten, so war es ihm doch eine unvergleichlich grössere Freude, dass er das Kloster Dünwald, welches seit mehreren Jahren dem Prämonstratenserorden und der Leitung der Abtei Steinfeld ganz entzogen war ${ }^{1}$ ), wieder in das alte Verbältnis zum Orden und zum Mutterhause zurtickführen konnte. Nachdem nachweislich schon seit dem 17. Januar 1251 wieder ein Prior an die Spitze des Kloster's getreten war"), wie es die Statuten des Ordens forderten, übte der Steinfelder Abt im Jahre 1254 als der verantwortliche Leiter sein Amt dort wieder aus, indem er zugleich mit dem Prior, dem Kellermeister, der Meisterin und Priorin des Dünwalder Konvents urkundlich erklärte, dass der Kölner Bürger Gerhard Albus seiner Schwester Gertrud und seiner Tochter Agnes, welche als Nonnen in Dünwald lebten, 1 Mark Leibrente zugesichert hatte ${ }^{3}$ ). Am 15. Mai 1257 war die Sache soweit gediehen, dass der Erzbischof Conrad die vollzogene Wiedervereinigung des Klosters mit Prémontré und Steinfeld durch Urkunde öffentlich bekannt machen konnte und die Bestimmung traf, es sollten alle Personen, welche in geistlichen oder zeitlichen Dingen dort ein Amt ausübten, desselben enthoben sein, wofern der Steinfelder Abt oder sein Stellvertreter es nicht für gut befand, sie in dasselbe wieder einzusetzen. Auf diese Weise sollten alle Ungehörigkeiten oder auch Ungerechtigkeiten, welche bei der Trennung der Dtinwalder Nonnen aus ihrem bisherigen Ordensverbande aus Irrtum oder Unwissenheit oder aus anderen Gründen vorgekommen waren, wieder gutgemacht werden und vergessen sein $^{4}$ ).

1) S. oben S. $85 \mathrm{f}$.

2) S. Annalen 41, S. 97 f. Zeitschr. des Berg. Geschichtsvereins 20, S. 69 f.

3) S. ebenda S. 70 f. Vgl. das Regest vom Jabre 1244 ebenda, S. 67.

4) S. Hugo, Probationes I, col. 541 sq. Knipping a. a. O. III, S. 263 Nr. 1948. Gemäss einer Aufzeichnung in der Handschrift Monasteria monialium sub Steinfeld (im Stadtarchiv zu Köln), vereinigte Erzbischof Conrad das Dünwalder Kloster bereits am 9. Mai 1250 wieder mit Steinfeld. L. Korth, welcher dieses Datum für richtig hält, glaubt, dass der Annalist Hugo in der erzbischöflichen Urkunde irrigerweise 1257 idus maii statt 1250 VII idus maii (=9. Mai) gelesen hat. S. Annalen 44, S. 109. $112 \mathrm{f}$. Dieser Versuch, die vorliegende Abweichung in der 
Ungefähr um dieselbe Zeit eröffnete sich anderswo der $\mathrm{St}_{1}$ felder Abtei ein neues Feld seelsorgerischer Wirksamkeit. Währ die Ortschaft Wehr im Kreise Mayen mit der Pfarre und $d$ ganzen Zehnten bereits im 12. Jahrhundert zum Kloster Steinf gehörte ${ }^{1}$ ), wurde die Seelsorge daselbst von einem Geistlichen Erzdiözese Trier ausgeübt. Aber am 26. Mai 1255 übertrug Erzbischof Arnold II. von Isenburg, gestützt auf das den Präm stratensern verliehene päpstliche Privileg ${ }^{2}$ ), die ständige Seclso dem Abte Lambert, welcher in der Folge zu diesem $Z_{w e}$ einen oder mehrere seiner Steinfelder Chorherren nach Wehr , sandte $\left.^{3}\right)$.

Wenn diese erzbischöfliche Massnabme die Voraussetzı zulässt, dass die Steinfelder Abtei wegen ibrer religiös-praktise] Seelsorgsarbeit sich eines guten Rufes erfreute, so darf man w hinzufügen, dass auch ihr Vorsteher Lambert persönlich in hok Ansehen stand und weithin grosses Vertrauen genoss. Denn Herren des Landes, Herzog Walram von Jülich, die Grafen F drich von Blankenbeim, Friedrich von Schleiden, Heinrich . Reifferscheid und Gerlach von Dollendorf, vereinbarten im Ja 1254, in der Abtei Steinfeld zusammenzukommen, um mit d

Datierung des berichteten Ereignisses zu erklären, mag als gelun zu bezeichnen sein, aber der von Korth angeführte Grund, dass , sächlich von $1251 \mathrm{ab}$ wieder Prioren an die Stelle der Pröpste tretı ist jedenfalls nicht durchschlagend. Vielmehr wäre es sehr gut mög gewesen, dass der Erzbischof, wenn auch schon seit 1251 wieder ger nete Verhältnisse im Kloster Dünwald herrschten, doch noch sechs Ja mit der öffentlichen Erklärung der restitutio in integrum wart einerseits $u m$ denen, welche die Losreissung vom Orden verschul hatten, eine gelinde Strafe aufzuerlegen, andererseits, um inzwisc zu prüfen, ob die Wiedervereinigung nach menschlichen Berechnun; Bestand haben würde.

1) S. Annalen 93 , S. 48 und oben S. 63.

2) S. oben S. 82.95 .

3) Aus dem Berichte der series praep. et abb. Steinf.: Sub abbate dilatavit sese vitis Steinfeldensis ad parochiam in Wehr, qr de consensu Arnoldi archiepiscopi Trevirensis 26. Maii 1255 obte canonici nostri exercere coeperunt, ergibt sich die Unrichtigkeit der frü (Annalen 93, S. 48) ausgesprochenen Ansicht. Der Text ist dort um ändern: [Man darf] „doch zweifellos mindestens die Möglichkeit ablei dass schon während der Regierungszeit Evervins die Pfarre Wehr Besitze des Steinfelder Klosters war". 
Die Prämonstratenserabtei Steinfeld im 13. Jahrhundert.

Abte die Beilegung einer Streitigkeit zu bezeugen, welche zwischen Jutta, der Witwe Johanns von Bedburg, und ihrem Bruder, Gerhard von Kempenich, ausgebrochen war ${ }^{1}$ ).

Lambert starb im Jahre 1258. Ein wichtiges Ereignis aus seiner Regierungszeit, die Ubernahme der Seelsorge in Wehr, ist in dem Chronodistichon der series praep. et abb. Steinfeldensium verewigt:

Est SteInfeLDensIs resIDentIa praesVLIs apta Wehr; VIVens aVXI, fata VaCare IVbent. 1258²).

\section{Die Abtei Steinfeld in der zweiten Hälfte des 13. Jahrhunderts.}

$$
\text { 8. Abt Goswin Ir. (1258-1272). }
$$

Der Nachfolger des Abtes Lambert, Goswin II., hatte schon vor der Ubernahme seines Amtes in Steinfeld hinreichend Gelegenheit gefunden, sich mit den Aufgaben und Pflichten eines Klostervorstehers gründlich vertraut zu machen. In den Jahren 1244 bis 1255 hatte er als Prior das Kloster Meer und von 1255 lis 1258 als Abt das Kloster Sayn geleitet ${ }^{3}$ ). Die praktischen lirfahrungen, welche er in diesen beiden Stellungen gesammelt batte, mussten $\mathrm{ibm}$ naturgemäss in dem grösseren Wirkungskreise, an dessen Spitze er durch die Wabl zum Abte des Steinfelder Klosters berufen war, sehr zustatten kommen und die Arbeit wesentlich erleichtern.

Zunächst war es ihm beschieden, durch drei Schenkungen deu irdischen Besitz des Klosters zu mebren. Der Ritter Hermann von Elz und seine Gemablin Clementia vermachten dem Kloster am 20. Oktober 1259 zu Monreal im Kreise Mayen testa-

1) S. Mittelrheinisches Urkundenbuch III, S. 928 Nr. 1277.

2) Seine sonstige Tätigkeit für die Tochterklöster Dünwald und Meer s. Annalen 44, S. 75 f. Zeitschrift des Berg. Geschichtsvereins 20, S. $72 \mathrm{Nr} .55$ (der in der Urkunde erwähnte Propst Gerhard ist nicht, wie Korth annimmt, Propst in Steinfeld, sondern Propst der Augustinerinnen zu St. Maria bei Andernach). H. Kelleter, Urkundenbuch des Stiftes Kaiserswerth, Bonn 1904, S. 61 f. Knipping a. a. O. III, S. 252 Nir. 1853.

3) S. Hugo, Annales II, col. 759. Keussen a. a. O. S. 52. 
mentarisch zwei jenseits der Mosel, Ellenz gegenüber ${ }^{1}$ ), im Gebiete und Zehntbezirke von Fankel im Kreise Kochem gelegene Weinberge mit der Auflage, dass aus ihren Erträgen jährlich im Herbst nach beendigter Weinlese das nötige öl für eine Lampe erworben werde, die Tag und Nacht vor einem Kruzifixe im Kloster brennen sollte. Wenn von dem Ertrage noch etwas übrig blieb, konnten die Brüder es nach freiem Ermessen zu ihrem eigenen Gebrauch oder für das Kloster verwenden ${ }^{2}$ ).

Am 28. Januar 1265 schenkte die Gräfin Margarethe von Are dem Kloster die Güter zu Klaffenkotten, welche ihr verstorbener Gemahl Lothar mit dem Burggrafen zu Köln, Heinrich von Arenberg, gegen den Wildbann in der Gemeinde Kommern eingetauscht batte ${ }^{3}$ ).

In demselben Jahre (1265) verpflichtete sich der Graf Walram von Monjoie mit seiner Gemablin Jutta, der Kirche zu Steinfeld jährlich 14 kölnische Denare zu zahlen ${ }^{4}$ ).

Sodann hatte der Abt Goswin die Genugtuung, dass der Erzbischof Conrad, welcher sicb dem Kloster gegenüber als Schuldner betrachtete ${ }^{5}$ ), ihm am 26. Oktober 1260 als Entschädigung für die grossen Aufwendungen, welche es aus seinen Gütern and Besitzungen für die Kriege des Erzbischofs und insbesondere für die Befestigung der Stadt Ahrweiler hatte machen müssen, die Befreiung von dem Zoll und der Akzise auf Wein und alle anderen Erzeugnisse in Abrweiler urkundlich verbriefte ${ }^{6}$ ).

1) Wegen der Weinberge, welche das Steinfelder Kloster in Ellenz besass, brach unter der Regierung Goswins ein neuer Streit mit dem Kastorstifte zu Karden aus (s. Annalen 93, S. 28 und 94, S. 8 f.). Denu die series praep. et abb. Steinf. berichtet: Goswinus defendit libertatem vinearum in Ellenz contra capitulum Cardunense. Aber leider sind weitere Nachrichten üher die Veranlassung, den Verlauf und Ausgang des Streites nicht erhalten.

2) S. Mittelrheinisches Urkundendenbuch III, S. 1084 Nr. 1501. Mitt. a. d. Stadtarchiv 3, S. 43. In demselben Jahre (7. März 1259) schloss Goswin gemäss einer kurzen Notiz in der series praep. et abb. Steinf. eine Gebetsverbrüderung mit der Benediktinerabtei Malmedy.

3) S. Annalen 23, S. 175 f. Mitt. a. d. Stadtarchiv 3, S. 51 f. S. oben S. 78 .

4) S. Schannat-Bärsch a. a. O. 1. Bd. 2. Abt., S. 604 .

5) S. oben S. 94 .

6) S. Annalen 66, S. 191 f. Knipping a. a. O. III, S. 286 Nr. 2130.

Tille a. a. O. I, S. 167. 
Im folgenden Jahre (27. Juli 1261) richtete der Erzbischof an seine Getreuen in Herl (im Landkreise Trier) die Aufforderung, fiir den Schutz der Güter und Rechte einzutreten, welche das Kloster Steinfeld dort besass, da sie wohlerworben und ihm von. seinen Vorfahren läng'st unwidersprochen zuerkannt seien ${ }^{1}$ ).

Unter dem Nachfolger Conrads, dem Erzbischof Engelbert II. von Falkenburg (1261-1274), brach zwischen dem Kloster Steinfeld und Conrad III. von Schleiden ${ }^{2}$ ), einem Sohne des Grafen Friedrich, welcher mit dem Abte Lambert im Jahre 1252 einen Vergleich geschlossen hatte $^{3}$ ), wegen des Klosterhofes Reipach ${ }^{4}$ ) in der Pfarre Sistig eine heftige Streitigkeit aus, welche sich mehrere Jahre hinzog. Während der Erzbischof seinen Truchsess Adam von Hard und seinen Ritter und Burgmannen Jakob von Hard, Theoderich und Embrico von Waggendorf und Theoderich von Firmenich nach Sistig entsandte, um durch sie beide Parteien vornehmen zu lassen, fanden sich dort im Auftrage der Parteien die Herren von Blankenheim, Manderscheid und Wildenburg gleichжeitig als Vermittler ein.

Vor dem Gerichtshofe legte zuerst der Herr von Scbleiden dur, dass der Abt wegen des Hofes Reipach verpflichtet sei, ihm Wagen und Pflüge zur Verfügung zu stellen, das Mehl auf seiner Mühle mahlen zu lassen, seine Hunde nach beendigter Jagd zu futtern und seine besondere Erlaubnis einzuholen, bevor er das eigene Holz im Walde fällen lasse. Ferner habe der Verwaltel des Hofes die Pflicht, an den drei jährlichen Gerichtstagen auf seinem Hofe in Sistig zn erscheinen, und die Leute des Klosters, die in seinem Gebiete die Klostergüter bestellten, seien seinem Hofe in Sistig zu Diensten und Abgaben verpflichtet.

Im Gegensatze zu diesen Forderungen erklärte sodann die Partei des Klosters, dass sie rechtlich zu nichts verpflichtet sei, da sie den Hof Reipach mit allem seinem Zubehör mehr als 200 Jahre ungestört besessen habe, wenngleich sie auch dem Herrn von Schleiden and anderen edlen Herren öfters aus freien Stücken Dienste geleistet habe. Indessen zeigte sie sich bereit,

1) S. Annalen 23, S. 174 f. Mitt. a. d. Stadtarchiv 3, S. 45. Knipping: a. a. O. III, S. 289 Nr. 2150.

2) S. Schannat-Bärsch a. a. O. 1. Bd. 2. Abt. S. 656 f.

3) S. oben S. $95 \mathrm{ff}$.

4) S. oben S. 64 . 
jährlich dem Herrn von Schleiden vier Wagenräder ohne Eisenbeschlag und 8 Malter Hafer $z u$ liefern, damit sie die auf seinem Gebiete gelegenen Wälder und Wiesen frei benutzen könne, ferner den Förstern jährlich 8 Sümmer Hafer und 16 Brode (panes vulgo dictos credemich) unter der Bedingung zu geben, dass ihr acht Bäume, vier Eichen- und vier Buchenstänme, in dem Forste des Herrn von Schleiden zum Fällen bezeichnet würden (arbores ad secandum dictos(!) werboima).

Weiter fügte die Partei des Klosters im einzelnen noch hinzu: der Verwalter des Hofes und die dem Kloster hörigen Leute, welche in dem Bezirke des Herrn von Schleiden wohnten, sollten für das zum Bau der Häuser notwendige Hol\% einen Obolus oder ein Brod an den Förster zahlen, der ihnen alsdann den notwendigen Bedarf anweisen werde; die Klosterleute durften in dem Walde des Herrn von Schleiden ohne dessen besondere Erlaubnis kein Holz für Schindeln fällen, während sie gehalten seien, auf seiner Mühle mahlen zu lassen und als Abgabe jährlich 1 Denar, ein Fastnachtshuhn ${ }^{1}$ ) und von den einzelnen Pflïgen je 3 Denare zu entrichten. Die Schöffen des Herrn von Schleiden aus der Ortschaft Sistig seien verpflichtet, jäbrlich am Feste des beiligen Andreas (30. November) auf dem Hofe Reipach zusammenzukommen und dort Recht zu sprechen, wofür sie die übliche Beköstigung und 8 Denare empfingen. Die Klosterleute, welche die Äcker des Herrn von Schleiden bestellten, seien mit ibren Guttern dem Hofe zu Sistig dienst- und abgabepflichtig, wie umgekehrt die Leute des Herrn von Schleiden, welche die Äcker des Klosters. bebauten, dem Hofe des Klosters. Weitergebende Rechte seien dem Herrn von Schleiden über das Kloster nicht zuzuerkennen, ebensowenig wie über die Klosterleute, welche die Güter des Klosters bestellten, mit der einzigen Ausnahme, dass die letzteren zum Hochgerichte zu erscheinen hätten.

Da nach diesen beiderseitigen Darlegungen die beiden Parteien über die einzelnen Punkte lange und heftig hin und her stritten, ohne eine Einigung herbeiführen zu können, kamen sie schliesslich darin tiberein, den Streit durch einen Schiedsspruch zu schlichten, und betrauten nit dieser Aufgabe unter Hinzu-

1) S. G. Grupp, Kulturgeschichte des Mittelalters. 3. Bd. Paderborn 1912, S. 452 . 
ziehung und Vermittlung des Herrn von Wildenburg den Truchsess Adam von Hard und den Ritter und Burgmannen Jakob von Hard als Vertreter des Klosters, sowie die beiden Ritter Heinrich ron Guntersdorf und Theoderich von Marmagen als Bevollmächtigte des Herrn von Schleiden. Dieselben erkannten nach sorgfältiger Beratung am 15. August 1267, dass das Kloster für die Benutzung der Wälder und Wiesen dem Herrn von Schleiden die Abgaben leisten solle, zu denen es sich selbst bereit erklärt habe, und dass es, wenn anch nicht auf Grund einer Rechtsptlicht, so doch um des lieben Friedens willen (quod dicitur mudsuna) auf dessen Mühle mahlen lassen oder an dessen Müller jährlich 6 Sümmer Weizen liefern solle, und zwar lediglich aus dem Grunde, weil ein Klosterbruder durch eigenes Verschulden schon seit acht Jahren dieses Quantum obne Wissen und Willen des Abtes und Konventes entrichtet habe. Im übrigen sollten das Kloster und die Klosterleute dem Herrn von Schleiden zu weiter nichts ver* pflichtet sein. Wenn aber beide Parteien sich gegenseitig Dienste irgendwelcher Art erweisen wollten, so dürfte dadurch niemand in seinen Rechten beeinträchtigt werden ${ }^{1}$ ). Die auf diese Weise erzielte Einigung war indessen nicht von langer Dauer. Um die neuerdings ausgebrochene Streitigkeit endgültig beizulegen, beschlossen die Parteien, die Grafen Wilhelm von Jülich und Philipp den Älteren, Herrn von Wildenburg, zu Schiedsrichtern zu ernennen und ihrem Urteile, wie es auch ausfallen möge, sich unbedingt $z u$ unterwerfen. Diese Richter stellten sich nach eingehender Prüfung vollständig auf den Standpunkt, den die Partei des Klosters im Jahre 1267 eingenommen und ausführlich dargelegt batte ${ }^{2}$ ), und erkannte demgemäss in diesem Sinne. Am 24. März 1270 verkündeten sie in Gegenwart zablreicher Herren aus dem Adel des Landes und der Vertreter des Klosters, des Priors Heinrich, des Pastors Heinrich, des Kellermeisters Gottfried und der beiden Laienbrüder Johannes und Thicard, das Urteil und

1) S. Annalen 23, S. $176 \mathrm{ff}$. Mitt. a. d. Stadtarchiv 3, S. $54 \mathrm{f}$.

2) Die einzige Abweichung bestand darin, dass 1267 den Klosterleuten zur Pflicht gemacht wurde, zum Hochgerichte zu erscheinen, während der neue Entscheid zu iudicium quod dicitur hoegerichte noch den Zusatz erhielt: et ad defensionem terrae, quae dicitur lantweriughe. Uber die Beschränkung des Kriegsdienstes der Bauern auf die Landesverteidigung s. Zeitschr. des Berg. Geschichtsvereins 21, S. 217. 
zählten in der ausgefertigten Urkunde alle Rechte und Pflichten des Klosters nochmals einzeln auf ${ }^{1}$ ).

Zuletzt stellten Conrad von Schleiden und die Vertreter des Klosters unter demselben Datum eine neue Urkunde aus, in welcher der Graf im Einverständnis mit seiner Gemablin Elise und seiner Mutter Aleidis versicherte, dass er für sich und seine Erben allen geltend gemachten Ansprüchen dem Kloster gegenüber für immer entsagt habe ${ }^{2}$ ) und die Entscheidung der Schiedsrichter unverbrüchlich beobachten werde, während gleichzeitig der durch die Steinfelder Chorberren vertretene Abt sich ebenfalls mit der getroffenen Entscheidung unbedingt einverstanden erklärte und gemäss ihren Bestimmungen stets handeln zu wollen versprach ${ }^{3}$ ). Damit war der lang ersehnte Friede endlich wiederhergestellt.

Seit der Regierung Goswins übernahm die Steinfelder Abtei in der Pfarrkirche zum heiligen Dionysius in Krefeld die ständige Ausübung der Seelsorge, nachdem der päpstliche Kardinallegat Petrus ${ }^{4}$ ) im Einklang mit dem vom Papst Honorius III. den Prämonstratensern verliehenen Privileg ${ }^{5}$ ) am 21. Januar 1248 die Meisterin des Stiftes Meer auf Grund des ihr zustehenden Patronatsrechts ermächtigt hatte, die Pfarrstelle nicht mehr mit fremden Geistlichen, sondern mit einem Chorherrn ibres Ordens zu beset\%en. Zur Regelung des rechtlichen Verhältnisses der Abtei zur Pfarre verfügte der Erabischof Conrad am 26. April 1260, dass der von der Meisterin dem zuständigen Archidiakon, dem

1) S. Lacomblet a. a. O. IV, S. 806 f. Nr. 671. Zeitschr. des Aachener Geschichtsvereins 11, S. 110.

2) Die früher erhobenen Forderungen, die er in der Urkunde noch einmal aufzählte, ergänzte er nunmehr durch die Mitteilung, dass der Abt verpflichtet sei, vorher seine Erlaubnis einzuholen, wenn er seine Schweine in die dem Kloster gehörigen, aber auf Schleidener Gebie gelegenen Wäldex zur Eichelmast treiben wolle, ferner von jedem Mansus des Hofes Reipach einen Denar als Abgabe zu entrichten und von den Klostergütern Kuttendal und Wolfskehl ihm gewisse Dienste zu leisten, während die Klosterleute, gleichviel, ob sie von ihm Güter in Besitz genommen hätten oder nicht, an den Gerichtstagen auf seinem Hofe in Sistig erscheinen müssten.

3) S. Annalen 23, S. 178 ff. Mitt. a. d. Stadtarchiv 3, S. 57. SchaunatBärsch a. a. O. 1. Bd. 2. Abt., S. 1010 ff.

4) S. oben S. 89 .

5) S. oben S. 82 und 95 . 
Domdecbanten von Köln, präsentierte und von ihm rechtmässig investierte Pastor persönlich in Krefeld die Seelsorge auszuüben labe und dafür den Teil der Einkünfte beziehen solle, welcher hisher den Vikaren zufloss, im iubrigen aber alle Lasten und Pflichten auf sich nehmen müsse, welche die Pfarre im allgemeinen ibren Vorgesetzten schuldig seien. Den Überschuss der Einkünfte hingegen hatte er an das Kloster abzuliefern ${ }^{1}$ ).

Wegen der Ausübung der Seelsorge wurde der Abt Goswin im Jahre 1271, als die Pfarre Rheindorf ${ }^{2}$ ) im Kreise Solingen neu zu besetzen war, in einen Rechtsstreit verwickelt, welcher zunächst allerdings das Kloster Dünwald ${ }^{3}$ ) anging, aber mit dessen Ausgang auch die Interessen des Steinfelder Mutterklosters eng verknüpft waren. Das Präsentationsrecht übten dort abwechselnd die Ritter Manfred von Rheindorf, das Kloster Dünwald und das Apostelnstift zu Köln aus. In dem genannten Jahre aber präsentierte das Dünwalder Kloster den Steinfelder Chorberrn Christian, wäbrend die beiden anderen Patronatsinhaber gleichzeitig ihre Kandidaten aufstellten. Den so entstandenen Streit entschied der Magister Hermann von Bonn, Kanonikus an St. Severin zu Köln, in seiner Eigenschaft als Vertreter des Dompropstes und Archidiakons ${ }^{4}$ ) Arnold von Looz am 16. September 1271 zugunsten des Steinfelder Chorherrn und verlieh ihm die Investitur ${ }^{5}$ ). Sechs T'age später (22. September) gab er dem Pfarrer zu Flittard ${ }^{6}$ ) im Kreise Mülheim a. Rh. und dem Magister Wilhelm von Reins-

1) S. Lacomblet a. a. O. II, S. $264 \mathrm{Nr} .471$. Knipping a. a. O. III, S. $283 \mathrm{Nr}, 2101$. H. Keussen, Geschichte der Stadt und Herrlichkeit Krefeld. Krefeld 1865, S. $50 \mathrm{ff}$. $61 \mathrm{ff} .83 \mathrm{ff}$., im Anhang die Urkunden I, II, III. Die (lückenhafte) Reihenfolge der Krefelder Pfarrer aus der Abtei Steinfeld s. bei Keussen, Kloster Meer S. 52 ff. J. F. Lefranc und J. P. Lentzen, Geschichte der Pfarreien des Dekanates Krefeld. M.-Gladbach, S. $120 \mathrm{f}, 146 \mathrm{f}$.

2) S. Fabricius a. a. O. S. 329.

3) Dass Goswin auch sonst in die Angelegenheiten des Klosters Dünwald eingriff, s. Zeitschr. des Berg. Geschichtsvereins 19, S. $175 \mathrm{ff}$; 20, S. $72 \mathrm{f}$. Aunalen 44, S. 33.

4) Das Dekanat Deutz, zu welchem die Pfarre Rheindorf gehörte, war ursprünglich in Besitze des Dompropstes. Später ging die Würde eines Archidiakons in diesem Dekanate an den Propst des St. Kunibertstiftes über. S. Fabricius a. a. O. S. 316.

5) S. Zeitschr. des Bergischen Geschichtsvereins 20, S. $75 \mathrm{f}$.

6) S. Fabricius a. a. O. S. 322. 
dorf, Pfarrer zu Ollheim ${ }^{1}$ ) im Kreise Rheinbach, den Auftrag, den Kanonikus Christian in die Pfarre Rheindorf einzuführen und im Besitze derselben mit kirchlichen Strafmitteln zu schützen ${ }^{2}$ ).

Kurz vor seinem Tode gewann Goswin ${ }^{3}$ ) eine neue klösterliche Genossenschaft für den Prämonstratenserorden, nämlich das Kloster Engelpforten an der Mosel im Kreise Kochern. Dasselbe war um das Jahr 1255 von dem Ritter Emmerich von Monreal gegrïndet und Zisterzienserinnen, welche ans dem Kloster Chumbd bei Simmern kamen, übergeben worden. Nach einigen Jahren aber kehrten die Schwestern in ibre Heimat zurück, da das Kloster wegen seiner Lage mitten im Walde sehr vereinsamt und zugleich nur mit sebr kärglichen Mitteln ansgestattet war. Nunmehr erwarb der Graf Philipp III. von Wildenburg. ${ }^{4}$ ) von den Erben des Ritters Emmerich die leerstehende Besitzung und fübrte im Jahre 1262 Dominikanerinnen aus Marienthal in den Ardennen in dieselbe ein. Aber auch diesmal nahm die nene Gründung keine günstige Entwicklung. Die Dominikanerinnen wurden aus dem Ordensverbande ausgestossen, weil sie ohne Wissen ibrer Ordensoberen nach Engelpforten übergesiedelt waren. In dieser traurigen Lage erbarmte sich der Abt Goswin der Verstossenen, vermutlich durch die Bitten seines Freundes Philipp bewogen. Auf seine Veranlassung und mit Zustimmung des Erzbischofs

1) S. ebenda S. 230.

2) S. Zeitschr, des Bergischen Geschichtsvereins 20, S. 76. Durch diese Massnahme scheint der Streit wegen der Kirche zu Rheindorf doch nicht geschlichtet zu sein. Denn in einer Urkunde vom 8. Mărz 1274 trat unter den genannten Zeugen Christian als Prior von Dünwald auf und am 7. Januar 1276 wurde von Schiedsrichtern dahin erkannt, dass der Kanonikus Pelegrin von St. Maria ad gradus im Besitze der Pfarre Rheindorf bleiben solle. S. ebenda S. 76 f.; Annalen 44, S. 28.

3) Wie sehr er es verstanden hatte, sich weit über seinen klösterlichen Wirkungskreis hinaus Ansehen und Einfluss zu verschaffen, zeigen die Anweisungen, welche der Papst Urban IV. ihm (in Verbindung mit dem Abte von Hamborn) gab, um die zerrütteten Finanzen des Kölner Erzstifts wieder in Ordnung zu bringen und den Erzbischof Engelbert zum Gehorsam gegen päpstliche Befehle zu zwingen. S. H. Finke, Westfälisches Urkundenbuch 5. Bd. 1. Teil Münster 1888, S. 291 Nr. 624. S. 292 Nr. 625. Böhmer a. a. O. S. 1437 Nr. 9209; S. 1447 Nr. 9305 u. Nr. 9306 ; S. 2143 Nr. 14913. Mon. Germ. hist. Epist. saec. XIII, tom. III, p. 501 sqq.

4) S. Schannat-Bärsch a. a. O. 1. Bd. 2. Abt, S. 1086. 
Heinrich von Trier traten sie im Jahre 1272 zu dem Prämonstratenserorden über und legten am Feste des beiligen Augustinus (28. August) die feierlichen Gelübde ab, ohne indessen in ein danerndes Abhängigkeitsverhältnis zu der Abtei Steinfeld zu treten. Denn als der Erzbischof später von einer Romreise zurückkebrte, fand er es für besser, sie der Abtei Sayn zazuweisen und unter die geistliche Leitung ihres zeitigen Abtes Conrad zu stellen ${ }^{1}$ ). Noch in demselben Jahre schied der Abt Goswin aus dem Leben.

\section{A bt Johann von Löwen (1272-1279).}

Ebenso wie sein Vorgänger, hatte der neu erwählte Abt Johannes, der aus Löwen gebürtig und in Floreffe in den Prämonstratenserorden eingetreten war, vor seiner Berufung nach Steinfeld schon eine ebrenvolle Laufbahn im Orden durchmessen. Nachdem er in Floreffe nacheinander die Ämter des Subpriors und Priors verwaltet hatte ${ }^{2}$ ), wurde er zuerst Propst in dem Prämonstratenserinnenkloster Wenau $^{3}$ ) im Kreise Düren, sodann Abt in Rommersdorf, 1268 Abt in Sayn und stand dieser Abtei nachweislich bis zum Feste des beiligen Martin (11. November) des Jahres 1273 vor. Da er aber spätestens seit Anfang Oktober 1272 auch in Steinfeld das Amt des Abtes ausübte ${ }^{4}$ ), ergibt sich, dass er von diesem Zeitpunkte ab bis zum November des folgenden Jahres die Leitung der beiden Abteien Sayn und Steinfeld, des Tochter- und Mutterklosters, gleichzeitig in Händen hatte ${ }^{5}$ ).

1) S. Hugo, Annales I, col. 171. II, col. 759. 856. Stramberg 1. c. II, p. $87 \mathrm{sqq}$.

2) S. Berlière 1. c. p. 117.

3) S. oben S. 76.

4) Gemäss einer Angabe der series praep. et abb. Steinf. bestieg er den Thron eodem anno (1272), quo in capitulo generali festo s. Dionysii celebrato obtinuit stabulum equorum, d. h. einen Stall in einem der Wirtschaftsgebäude des Klosters Prémontré, in welchem er für die Dauer des Generalkapitels seine Pferde unterbringen konnte. Vgl. die Urkunde des Generalabts Johannes vom 9. Oktober 1250 für den Abt von Knechtsteden und den Propst von Heinsberg bei Ehlen a. a. O. S. $38 \mathrm{Nr}$. IL.

5) S. die series praep. et abb. Steinf. Berlière 1. c. p. 117. Hugo widerspricht sich selbst, wenn er (Annales I, col. 85) die von Johannes verwalteten Åmter in der Reihenfolge aufzählt: Ex illa [praepositura Winagiensi] ad Saynensem abbatiam translatus fuerat, inde ad Rommers- 
Auf seine Bitten erteilte der Papst Johann XXI. am 30. November 1276 dem Steinfelder Konvent die Vollmacht, mit Aus. nahme der Lehngüter alle beweglichen und unbeweglichen Güter, welche die Chorherren und Konversen, bevor sie die Welt ver. liessen und in Steinfeld eintraten, als Erbe oder auf einen anderen gerechten Titel besassen und demgemäss nach eigenem Gutdünken auf andere hätten übertragen können, von ihnen sich als Eigentum zu erbitten, anzunehmen und zu behalten ${ }^{1}$ ).

Sonst ist, abgesehen davon, dass er eine mit der Stadt Ahr weiler über die dort gelegenen Klostergüter ausgebrochene Streitig. keit auf gütlichem Wege schlichtete ${ }^{2}$ ) und zugunsten des Klosters Dünwald mehrere Schenkungs- und Kaufverträge bestätigte ${ }^{3}$ ), keine Spur seiner Tätigkeit in Steinfeld erhalten geblieben. Er muss jedoch in dem Rufe eines tüchtigen Oberen gestanden haben, da die Abtei Floreffe, aus welcher er hervorgegangen war und welche selbst als eins der drei ältesten Prämonstratenserstifter (neben Prémontré und Laon) ein bohes Ansehen genoss, ihn zu ihrem Vorsteher erwählte. Gemäss den Annales Floreffienses ${ }^{1}$ ) wurde diese Wahl am 14. September 1289 getätigt, nachdem der bisherige Abt freiwillig von seinem Amte zurïckgetreten war. Indessen hatte Johannes zweifellos schon vor diesem Termine die Leitung des Steinfelder Klosters niedergelegt, da hier sein Nachfolger Wimar als regierender Abt unter dem 30. April 1289 zwei Urkunden ausstellte und mit dem Abtsiegel versah ${ }^{5}$ ). Die Über-

dorfiensem, postea ad Steinfeldensem und andererseits (Annales II, col. 855) von ihm sagt: Ex Saynensi abbatia Steinfeldiam postulatus accessit.

1) S. Annalen 23, S. 180 f.; Mitt. a. d. Stadtarchiv 4, S. 6.

2) S. die Originalurkunde im Staatsarchiv zu Koblenz. B. B. Erzstift Köln 23; ferner die series praep. et abb. Steinf. Hugo, Annales II, col. 856.

3) S. Zeitschrift des Berg. Geschichtsvereins 19, S. 178 ff. 20, S. 76 ff. Annalen 44, S. 78 f.

4) S. Mon. Germ. hist. script. XVI, p. 629.

5) S. unten S. 117. Die in der weiteren Darstellung erwähnten (acht) Urkunden, welche in den Jahren 1281-1287 ausgefertigt wurden, geben über diese Frage keinen Aufschluss, da der Steinfelder Abt in ihneb überhaupt nicht oder nur als abbas monasterii Steinveldensis, ohne Angabe seines Namens, genanıt ist. 
lieferung verlegt seine Abdankung in Steinfeld in das Jahr 1279¹). tuf seine Amtsführung in Sayn, Steinfeld und Floreffe sowie seine Amtsniederlegung tnd sein Todesjahr weist ein Chronogramm in der series praep. et abb. Steinfeldensinm mit den Worten bin:

In SaIna, SteInfeLD et FLoreff VIXIt Vt abbas, DeposIto baCVLo tVtIVs astra petIt ${ }^{2}$ ). 1293.

\section{A bt Wimar (1279-1298).}

An die Stelle des nach Floreffe übergesiedelten Abtes Johannes trat durch die Wahl der Steinfelder Chorherren der dbt Wimar, dessen lange Regierungszeit von grosser Bedeutung fuir die Entwicklung der Abtei Steinfeld war. Zahlreiche Urkunden legen Zeugnis dafür ab, dass unter ihm durch Verkauf, 'Tausch und Verpachtung, durch Ankauf und Schenkung eine erhebliche Verschiebung in dem klösterlichen Eigentum vor sich ging.

Dass die Abtei in der Stadt Köln Besitzungen batte, ergibt sich aus einem Vertrage, welchen der Abt am 3. Januar 1285 mit den Eheleuten Ludwig und Gertrud in Köln abschloss, indem er ihnen den dritten Teil eines steinernen Hauses und eine Hofstätte auf der Johannesstrasse ${ }^{3}$ ) sowie den dritten Teil eines Backhauses mit der zugehörigen Hofstätte auf der Maximinenstrasse verkaufte ${ }^{4}$ ).

An den Herrn Theoderich von Kerpen und dessen Schwager, den Ritter Johannes von Walthechin, verkaufte Wimar am 18. April 1288 für 200 Mark den Klosterhof in Berndorf im Kreise Daun mit sämtlichem Zubebör, Feldern, Weiden, Wiesen, bebautem und unbebautem Ackerland, Zehnten, Renten und dem Patronatsrecht

1) Nachdem Johannes in Floreffe sein Amt mit glänzendem Erfolge ausgeübt, insbesondere eine vorzügliche Ordensdisziplin geschaffen und ein reiches wissenschaftliches Leben in dem Stifte gepflegt hatte, legte er im Jahre 1291 freiwillig die Abtswürde nieder, führte ein zurückgezogenes Leben und starb eines heiligen Todes am 27. August1293. s. Berlière 1. e. p. 117. Barbier l. c. p. $157 \mathrm{sqq}$.

2) Die Abtei Parc feierte sein Gedächtnis am 26. Juli. S. van Waefolghem l. c. p. $304 \mathrm{sq}$.

3) S. H. Keussen, Topographie der Stadt Köln im Mittelalter, 2. Bd. Bonn 1910, S. 95 Nr. 67. 68.

4) S. ebenda S. 133 Nr. 9. 10.11. L. Ennen, Quellen zur Geschichte der Stadt Köln, 3. Bd. Köln 1867, S. 214 Nr. 247. 
über die Pfarrkirche ${ }^{1}$ ). Falls die beiden Käufer, welche je zur Hälfte alle Erträge des Hofes erhielten, sich über die Besetzung der Pfarre nicht einigen konnten, entschieden sie durch Los, wer von ihnen in diesem Falle das alleinige Recht ausüben solle einem wissenschaftlich gebildeten und würdigen Kleriker das Pfarramt zu übertragen ${ }^{2}$ ).

Am 25. Mai 1290 übertrug Wimar in Gegenwart des Steinfelder Chorherrn Johannes, des zeitigen Pastors von Ripsdorf, die Klostergüter in Hüngersdorf im Kreise Schleiden, welche der verstorbene Ritter Gerlach von Stalhoven mit seiner Gemahlin Guda zugunsten der Kranken geschenkt hatte, an Heinrich, den Sohn des verstorbenen Micahel mit der Auflage, jährlich am Feste des heiligen Andreas (30. November) 18 Schillinge an das Kloster für die Kranken zu zablen. Falls dieser in der Zahlung der Rente säumig war, batte das Kloster das Recht, die Güter zurückzunehmen, zu behalten und zum eigenen Nutzen zu verwenden, sowie für alle etwa entstandenen Schäden for dem kirchlichen und weltlichen Gericht Ersatz zu fordern. Nach seinem Tode aber erbielten seine Söhne oder Erben die Güter zurück und latten als Kurmede eine Mark zu zahlen ${ }^{3}$ ).

Auf Grund eines Vertrages vom 27. Dezember 1292 tauschte Wimar 6 Morgen Wiesen aus dem Klosterbesitze zu Oberbolheim im Kreise Düren gegen 6 andere Morgen Wiesen ein, welche dem Ritter Arnold Spee von Bolheim gehörten, und bezog fortan einen jäbrlichen Zins von 12 Denaren, weil der Ritter auf den Klosterwiesen ein Haus erbaut, einen Hof angelegt und die ganze Besitzung mit einem Graben umgeben und stark befestigt hatte ${ }^{4}$ ).

1) Die Pfarrei Berndorf gehörte nachweislịch schon zu dem Kloster Steinfeld, als dieses noch von Augustiner-Chorherren bewohnt war (1097-1121). S. Annalen 93, S. 17. 20.

2) S. die Originalurkunde im Freiherrlich von Solemacherschen Archiv zu Büllesheim. Die Urkunde, auf welche Herr Archivar Dr. Keussen in Köln mich aufmerksam zu machen die Güte batte, stellte mir Herr Freiherr von Solemacher bereitwilligst zur Verfügung. Beiden Herren sei hiermit herzlicher Dank gesagt.

3) S. Annalen 19, S. 314. Die Originalurkunde befindet sich im Germanischen Nationalmuseum zu Nürnberg (Reg. Rep. Nr. 9009). Gütige Mitteilung des Herrn Archivars Dr. Hermann Keussen in Köln.

4) S. Annalen 23, S. 187. Mitt. a. d. Stadtarchiv 4, S. 30. 
Drei Jahre später (1295) vertauschte Wimar 50 Morgen Ackerland bei Sinzig gegen den Hof Diefenthal bei Wehr. Da der bisherige Inhaber, der Ritter Heinrich der Gude, denselben von dem Reiche zu Lehen trug, bestätigte der König Adolf von Nassau am 2. Dezember 1295 den Tauschvertrag, löste den Hof ron allen Lehensverbindlichkeiten und trug die Ländereien zu Sinzig dem Reiche als Lehen auf ${ }^{1}$ ).

Durcb einen Pachtvertrag, den Wimar am 16. März 1286 mit Reinhard von Westerburg, dem Propste und Archidiakon des Kassiusstiftes in Bonn schloss, erhielt die Abtei eine Besitzung in Oberbachem, mit welcher das Patronatsrecht über die Pfarrkirche in Franken ${ }^{2}$ ) im Kreise Abrweiler verbunden war. Dafür musste sie jährlich am Feste Allerheiligen einen Zins von 30 Schillingen an das Stift entrichten und ihre Zustimmung dazu geben, dass die genannte Besitznng und die sonstigen Güter, welche sie von alter's her in Bachem besass ${ }^{3}$ ), mit Ausnahme der ihr von Heinrich von Reifferscheid testamentarisch vermacbten ${ }^{4}$ ), dem Stifte verpfändet würden, wenn sie bis zum 30 . November ihren Verpflichtungen nicht nachgekommen wäre ${ }^{5}$ ).

Weiter erwarb der Abt Wimar für eine Kanfsumme von 80 Mark von den Erben des Edlen Matthias von Calmunth am 18. April 1285̃ die Vogtei iiber die Ortschaft Wehr und eine jührliche Rente von 6 Maltern Weizen und 1 Fuder Wein ${ }^{6}$ ). Am 18. August 1289 kaufte er für 340 Mark von Arnold, dem Magister und Dechanten des Stiftes zum hl. Dionysius in Lüttich, sïmtliche Güter, welche das Stift in dem Dorfe und auf dem Hofe Bengen bei Ahrweiler besass, bestehend in Äckern, Weingärten, Zehnten, Renten, Wäldern samt den angesiedelten Knechten nnd dem Patronatsrecht über die Pfarrkirche ${ }^{7}$ ). Zuletzt erstand

1) S. Günther l. c. II, p. 510 Nr. 362.

2) S. oben S. 64 .

3) S. ebenda.

4) S. oben S. $97 \mathrm{f}$.

5) S. die Originalurkunde Nr. 22 im Staatsarchiv zu Düsseldorf.

6) S. Annalen 66, S. 192 f. Tille a. a. O. I, S. 168.

7) S. die Orjginalurkunde im Kölner Stadtarchiv. Mitt. a. d. Stadtarchiv 4, S. 25. Die Gründe, weshalb das Lütticher Stift seine Güter in Bengen gern verkaufte, s. Annalen 23, S. 183. Mitt. a. d. Stadtarchiv 4, S. 23. 
er am 25. April 1295 von dem Abte Adolf von Siegburg für eine Summe von 200 Mark eine Rente von 100 Maltern Weizen, welche sechs Jahre lang aus den Zehnten der Pfarreien Hochkirchen und Rövenich zu entrichten war ${ }^{1}$ ).

$\mathrm{Zu}$ diesen durch Kauf erworbenen Gütern kamen noch andere durch Stiftung und Schenkung seitens woblhabender. Gönner hinzu. Der Edelherr Adolf von Dollendorf, welcher Kanonikus in St. Gereon in Köln gewesen war und im Begriffe stand, in Steinfeld in den Prämonstratenserorden einzutreten ${ }^{2}$ ), übergab dem Abte Wimar zum Ankaufe eines Gutes die Summe von 400 Mark und behielt sich von ihr - mit einer geringen Ausnahme - für die Zeit seines Lebens den Genuss der Ein. künfte vor, eine Vergünstigung, welche ihm mit Riicksicht auf seine edle Abkunft bereitwillig eingeräumt wurde (ntpote ei qui de moribus delicacioribus ad monasterium transiit uberius providea tur). Nach seinem Tode aber sollten aus den Erträgen jälrlich 4 Fuder gewöhnlichen Weins und $10 \mathrm{Om}$ besseren Wachstums als Pitanz für den Konvent beschafft und wöchentlich 2 Sümmer Brod an der Klosterpforte an die Armen verteilt werden. Der Abt, welcher die Stiftung am 19. Juni 1290 im Namen des Konventes annahm, legte von dem empfangenen Gelde 250 Mark in den eben genannten Gütern in Bengen an und verwandte die übrigen 150 Mark zu verschiedenen Zwecken des Klosters. Als Gegenleistung übernahm er gemäss dem Wunsche des Stifters die Pflicht, das Gedächtnis seiner Eltern und Wohltäter und aller armen Seelen sowie nach dem Tode des Stifters auch dessen Gedächtnis jährlich mit besonderer Feierlichkeit zu begehen und allen diesen Verstorbenen alle 14 Tage in Konvente ein spezielles memento in der Vigil, der Messe und der commendatio zu widmen ${ }^{3}$ ).

Der Ritter Wilhelm von Froitzheim, Schenk in Nideggen, machte am 18. Januar 1291 seinen in Scheidweiler im Kreise Düren gelegenen Hof mit Äckern, Gerechtsamen und allem $\mathrm{Zu}$ behör dem Kloster unter der Bedingung zum Geschenke, dass regelmässig an dem Tage seines Jahrgedächtnisses und an den

1) S. Tille a. a O. I, S. 168. Über die Zehntrechte der Abtei Siegburg in den Pfarreien Hochkirchen u. Rövenich s. Fabricius a. a. O. S. 34 u. 231.

2) Seine Lebensschicksale, insbesondere seine wechselvolle Laufbahn im Prämonstratenserorden s. unten S. $121 \mathrm{ff}$.

3) S. die Originalurkunde $\mathrm{Nr} .27$ im Staatsarchiv zu Düsseldorf. 
Jalırestagen des Todes seines Vaters, seiner Mutter, seiner beiden Frauen Mechtildis und Aleidis und seiner Kinder 3 Mark für cine besondere Beköstigung der Chorherren im Refektorium ausyelegt würden ${ }^{1}$ ).

Ferner schenkte der Edle Ropert von Rosowe am 25. April 1292 dem Kloster seinen Hof und alle seine Guiter in Fritzdorf ${ }^{2}$ ) im Kreise Rheinbach samt dem Patronatsrechte über die Pfarrkirche, so dass der Ritter Johann von Hammerstein, dessen Bruder Gundolf und Verwandter Arnold, welche diese Güter bisher von dem Geschenkgeber zu Lehen hatten, sie in Zukunft aus der Hand des Klosters zu Leben nehmen mussten ${ }^{3}$ ).

Da die Genseinde Fritzdorf in der Grafschaft Neuenahr lag und die Pfarrkirche zum Dekanat Ahrgau, mithin zum Archidiakonatsberirk des Propstes von St. Kassius in Bonn gehörte ${ }^{4}$ ), bestätigten der Graf Wilhelm von Neuenahr und der Propst und Archidiakon Reinard am 1. November 1295 auf Bitten des Klosters die vollzogene Schenkung. Die bisherigen Vasallen und Lehensherren leisteten dem Abte von Steinfeld die Hulde und den Eid der Treue und gaben sodann, ein jeder den erhaltenen Teil seiner Güter, in die Hände des Abtes zurück, nachdem sie mit einer beiderseits vereinbarten grossen Geldsumme abgefunden waren ${ }^{5}$ ).

Der bisherige Pastor von Fritzdorf aber, Hermann mit Namen, legte mit Zustimmung des Erzbischofs Sigfried von Köln und des Archidiakons Reinard sein Amt nieder und übertrug alle seine Einkünfte und Rechte an das Kloster Steinfeld gegen eine jährliche Rente von 55 Mark, die zur Hälfte je am Ende des Monats Mai und am 11. November an ihn in Koblenz oder Köln zu entrichten war. Zudem verpfändete der Abt Wimar ihm am 27. Oktober 1295 als Sicherheit die drei dem Kloster gehörigen Höfe in Ellenz, Edeger und Crör an der Mosel mit der weiteren Verpflichtung, dass er die fällige Rente ans den sonstigen Klostergütern bestreiten werde, wenn diese Höfe etwa infolge von räu-

1) S. Annalen 23, S. 185. Mitt. a. d. Stadtarchiv 4, S. 26 f. Zeitschr. des Aachener Geschichtsvereins 12, S. 186.

2) S. Fabricius a. a. O. S. 137.

3) S. Hugo, Annales II, col. 870 sq. Annalen 23, S. 186. Mitt. a. d. Stadtarchiv 4, S. 28.

4) S. Fabricius a. a. O. S. 127.

5) S. Annalen 23, S. 187 ff. Mitt. a. d. Stadtarchiv 4, S. $34 \mathrm{f}$. 
berischen Einfällen, allgemeiner Unfruchtbarkeit, grosser Feversbrunst oder anderen Schicksalsschlägen keinen Ertrag abwerfen würden ${ }^{1}$ ).

Endlich schenkte der Edelberr Johannes von Reifferscheid mit seiner Gemahlin Cunigunde und seinem erstgeborenen Sohne Johannes ${ }^{2}$ ), dem Erben der Herrschaft Reifferscheid, am 20. März 1294 dem Kloster seinen Hof und alle seine Güter in Dreis bei Rheinbach mit dem Patronatsrecht über die dortige Pfarrkirche ${ }^{3}$ ) und allen zu dem Hofe und den Gütern gehörigen Lehensleuten ${ }^{*}$ ).

Wegen der Mühle zu Oberbolheim, welche die Abtei im Jahre 1196 von dem Adalbertstift in Aachen in Erbpacht genommen hatte ${ }^{5}$ ), geriet der Abt Wimar vorübergehend in Streit mit dem Dechanten Gerhard, dem Vertreter dieses Stiftes. Gemäss dem schriftlich vorliegenden Vertrage batte das Kloster 1/2 Mark Kurmede an das Stift zu zablen, "si abbas praefati monasterii obierit". Während das Kloster den Ausdruck obire im bucbstäblichen Sinne (= sterben) fasste, behauptete der Dechant Gerhard, dass mit diesem Ausdruck im weiteren Sinne gemeint sei: wenn der Abt stirbt oder abgesetzt wird oder sein Amt niederlegt oder aus irgendeinem anderen Grunde aufbört, Abt zu sein, oder auch, wenn ihm ein anderer Abt zur Seite gestellt wird, weil er krank oder unfähig ist.

Um dem Streite ein Ende zu machen, kamen beide Parteien sich in der Weise entgegen, dass der Abt von Steinfeld die Auslegung des Dechanten Gerhard als richtig anerkannte und dieser seinerseits den Betrag der zu zahlenden Kurmede herabsetzte. Demgemäss hatte fortan auf Grund eines neuen Vertrages, welcher

1) S. die Originalurkunde Nr. 29a im Staatsarchiv zu Düsseldorf.

2) Wahrscheinlich war dieser Edelherr Johannes derselbe, welcher die oben (S. 98) erwähnte Schenkung seines Onkels Heinrich bestätigte. Wenn er nach Schannat-Bärsch (a. a. O.1. Bd. 2. Abt. S. 623) mit Adelheid vermählt war, die ihm einen Sohn Johannes schenlste, während diese Urkunde als seine Gemahlin Kunigunde (und als Sohn Johaunes) bezeichnet, so ist, vorausgesetzt, dass jene Nachricht richtig ist, wohl anzunehmen, dass er zweimal verheiratet war.

3) Vielleicht ist die alte, ausserhalb der Stadtmauer von Rheinbach gelegene Pfarrkirche von St. Martin gemeint, welche 1789 durch Feuersbrunst eingeäschert wurde. S. Fabricius a. a. O. S. 149.

4) S. die Originalurkunde Nr. 29 im Staatsarchiv zu Düsseldorf.

5) S. oben S. 67. 
am 30. April 1289 abgeschlossen wurde, das Kloster jedesmal, wenn der Abt von seinem Amte zurücktrat, gleichviel ans welchem Grunde, innerhalb sechs Wochen vom Tage der Wahl des neuen Abtes ab gerechnet an den Amtmann des Stiftes in Lendersdorf ${ }^{1}$ ) bei Düren eine Abgabe von 4 Schillingen zu entrichten ${ }^{2}$ ).

Ausserdem erkannte Wimar mit seinem Prior Heinrich unter demselben Datum an (30. April 1289), dass das Steinfelder Kloster wegen drei bei der Mühle von Oberbolbeim gelegenen Hofstätten, die es ebenfalls in Erbpacht besass, jährlich am Feste des bl. Martinus an das St. Adalbertstift 9 Denare und drei Hühner und an den Vogt seines Hofes in Lendersdorf $1 / 2$ Malter Malz zu liefern hatte, um so von allen Verpflichtungen gegen die Gerichtsvogtei entbunden zu sein ${ }^{3}$ ). Und damit die geschlossenen Verträge gewissermassen anch eine religiöse Stütze erhielten und äusserlich erkennbar werde, von welchem Vertrauen und Wohlwollen die beiden Parteien zu einander beseelt seien, nahm Wimar am 13. Mai 1289 den Dechanten und sämtliche Kapitulare des Adalbertstifts in die Gehetsverbrüderung auf ${ }^{4}$ ).

Nachdem der Erzbischof Sigfried die Kirche Mersburden bei Zülpich, über welche die Steinfelder Abtei seit dem Jahre 1208 das Patronatsrecht besass ${ }^{5}$ ), hatte niederreissen lassen, weil er wegen ihrer allzu grossen Nähe bei dem Orte Zülpich, der seiner Herrschaft unterstand ${ }^{6}$ ), für sich und die Erzdiözese grosse Gefahren befürchtete, denen er zuvorkommen wollte ${ }^{7}$, übertrug er ihr

1) S. Fabricius a. a. O. S. 76.

2) S. Quix 1. c. Tom. I, Pars II Aquisgrani 1840, p. 160 Nr. 234. Annalen 23, S. 183 f. Mitt. a. d. Stadtarchiv 4, S. $24 \mathrm{f}$.

3) S. Quix 1. c. p. $161 \mathrm{Nr} .237$. An das Apostelnstift in Köln hatte die Abtei Steinfeld (nach einem Verzeichnis der Renten, Zinsen und soustigen Einkünfte vom Jahre 1293) jährlich von 15 Morgen Ackerland, die zwischen Wissersim und Vint gelegen waren, 2 Malter Weizen und 1 Sümmer Winterweizen abzuliefern. S. Ennen, Quellen 3. Bd., S. 355 Nr. 395.

4) S. Quix l. e. p. $160 \mathrm{Nr} .233$.

5) S. oben S. 70 .

6) S. Zeitschr. des Aachener Geschichtsvereins 11, S. $117 \mathrm{f}$. Annaleu 67, S. 26.

7) Um in den Kämpfen gegen die Grafen von Jülich an der Stadt Zülpich einen festen Stützpunkt zu haben, befestigte er sie im Jahre 1278 und erbaute in ihr eine starke Burg. S. Broix a. a. O. S. $94 \mathrm{f}$. 
als Entschädigung den in Zülpich gelegenen Grund und Boden, welchen der Schenk von Nideggen, Wilhelm Wetzstein ${ }^{1}$ ), von ibm zu Lehen trug. Darauf liess der Abt auf diesem Grundstiick eine neue Pfarrkirche errichten, über welche er wiederum das Patronatsrecht erhielt, und einen Friedhof anlegen, während der Schenk von Nideggen durch Urkunde vom 15. September 1285 für sich und seine Erben auf alle Rechte, die er an dem Grundstück batte, freiwillig Verzicht leistete, zumal ihm als Ersatz für einen jährlichen Zins von 12 Denaren und einem Kapaun, welchen er bis dahin von der Kölner Kirche wegen des Grundstïckes als Lehen bezogen batte, von dem Abte ein jührlicher Zins aus zwei unter einem Dache befindlichen, auf der Strasse Aterpech in Zülpich gelegenen Häusern und zwei angrenzenden Hofstätten angeboten wurde $^{2}$ ), eine Vereinbarung, welche am folgenden Tage (16. September) vou dem Erzbischof Sigfried gutgeheissen und bestätigt wurde ${ }^{3}$ ).

Wegen der Pfarrei Hochkirchen, über welche das Kloster Steinfeld seit dem Jabre 1194 das lalbe Patronatsrecht besass ${ }^{4}$ ), sah sich Wimar genötigt, die Hilfe des Kölner Dompropstes anzurufen, weil dieser in dem Dekanate Bergheim, zu welchem Hochkirchen damals gehörte, das Amt des Archidiakons versah. In dieser Pfarrei übte ein Priester namens Heinrich die Seelsorge aus, wabrscheinlicb auf Veranlassung der Abtei Siegburg und der Herren von Jülich, Wickrath und Kenten, denen die andere Hälfte des Patronatsrechts zustand ${ }^{5}$ ). Von seiten des Archidiakons aber war auf Präsentation des Abtes Wimar der Steinfelder Chorherr Gumpert zngelassen und investiert, nachdem er die Pfarrgeschäfte persönlich zu besorgen versprochen hatte. Infolgedessen liess der Archidiakon durch seinen Offizial am 28. Mai 1287 dem Dechanten des Dekanates Bergheim, dem Propste Werner von St. Gereon in Köln, unter Strafe der suspensio ab officio den Auftrag zugehen, den Priester Heinrich aufzufordern, innerhalb acht Tagen von der

1) Weitere Nachrichten über ihn s. in der Geschichte der Familie Scheuk von Nideggen S. $30 \mathrm{f}$.

2) S. Annalen 23, S. 181 f. Mitt. a. d. Stadtarchiv 4, S. 34.

3) S. die Originalurkunde im Kölner Stadtarchiv; Mitt. a. d. Stadtarchiv 4. S. 1 อ.

4) S. oben S. 65 .

5) S. Fabricius a. a. O. S. 34 . 
Leitung der Pfarrei zurïckzutreten und den Steinfelder Kanonikus all der Übernahme und Ausübung des Pfarramtes nicht zu hindern 1 ).

Den empfangenen Auftrag gab der Propst und Dechant Werner am 3. Juli an seinen Stellvertreter im Dekanate Bergheim ${ }^{2}$ ) weiter und fügte seinerseits den Befehl hinzu, den Kanonikus Gumpert sofort als Pastor von Hochkirchen ins Landkapitel anfyunehmen und seine Anerkennung von allen Kapitelsmitgliedern zu fordern. Wenn der Priester Heinrich unter Vorschützung eines bestimmten Grundes nicht Folge leiste, solle er ibm unrerzüglich davon Mitteilung machen und beide Parteien nach Ansctzung eines Termins zur Untersuchung der Sache an ihn verweisen ${ }^{3}$ ). Der Ausgang der strittigen Angelegenheit ist unbekannt.

Am 1. Mai 1289 wurde dem Abt Wimar eine Schenkung angeboten, die von dem grossen Vertrauen Zeugnis ablegte, dessen sich die Steinfelder Abtei als religiöse Genossenschaft erfreute. Da das Zisterziensernonnenkloster Frauenkron (oder Marienkron) im Kreise Schleiden, welches walurscheinlich den Edelherren von Dollendorf seine Entstehnng und Ausstattung verdankte, im Laufe der Jahre hinsichtlich der Zahl seiner Mitglieder so zurückgegangen und in seinen zeitlichen und geistlichen Angelegenheiten so verwahrlost war, dass für die Zukunft ein kräftiger Aufscbwung zı einem blühenden klösterlichen Leben nicht mehr zu erwarten stand, tibertrugen die Klosterschwestern mit Zustimmung des Grafen Gerlach von Dottendorf und seines Bruders Adolf durch einen Schenkungsvertrag ihr ganzes Besitztum mit dem Patronatsrecht über die benachbarte Pfarrei Alendorf an das Kloster Steinfeld, damit es seiner religiös-kirchlichen Bestimmung, dem Dienste Gottes, erhalten bleibe ${ }^{4}$ ). Ob der Steinfelder Abt die Schenkung annahm und welchem Zwecke er sie in diesem Falle dienstbar

1) S. die Originalurkunde Nr. 23 im Staatsarchiv zu Düsseldorf.

2) S. Fabricius a. a. O. S. 17. Annalen 82, S. 137. 139 ff. Die bereits von Füssenich (ebenda S. 140) festgestellte Tatsache, dass ein solcher Stellvertreter selbst zuweilen auch den Titel decanus führte, wird durch die Formel der intitulatio und inscriptio von neuem bestätigt: W[ernerus] dei gracia prepositus ecclesie saucti Gereonis Coloniensis viro discreto decano christianitatis in Bergheym salutem in domino.

3) S. die Originalurkunde Nr. 24 im Staatsarchiv zu Düsseldorf.

4) S. J. Becker, Geschichte der Pfarreien des Dekanates Blankenheim. Köln 1893, S. 146. Schannat-Bärsch a. a. 0. 3. Bd. 1. Abt. 1. Abschn., S. 133 f. 
machte, lässt sich wegen Mangels an urkundlichem Material nicht ermitteln. Nur so viel ist gewiss, dass der Komtur der Johanniter zu Adenau, an welchen der Graf Gerlach 1299 seine Rechte ab. trat, die Pfarrei Alendorf später regelmässig besetzte, nachdem auch der Abt von Malmedy, der bisherige Kollator der Pfarre, seine Rechte im Jahre 1317 ibm übertragen hatte ${ }^{1}$ ).

Ausser dem Mutterhause Steinfeld, welches wegen der Vielseitigkeit der zu lösenden Aufgaben an die Arbeitskraft seines Abtes hohe Anforderungen stellte, nahmen auch die Tochte:klöster seine Aufmerksamkeit immerfort in Auspruch. Inshesondere scheint ihm das Stift Strabow in Prag grosse Sorge bereitet za haben, da er auf verschiedenen Visitationsreisen, welche er dorthin unternahm, sich genötigt sah, vier Äbte wegen schlechter Vermögensverwaltung abzusetzen, die Abte Friedrich (1283), Hermann (1285), Jordan (1288) und Luthold (1290) ${ }^{2}$ ). Für das Kloster Meer, welches mit dem Ritter Heinrich Beyger in eine heftige Fehde geraten war, trat er mit dem Abte von Altenberg und dem Kommandator des Johanniterhospitals in Neuerburg (in novo castro) als Schiedsrichter auf und fällte am 26. März 1286 einen Spruch, dem beide Parteien sich unterwarfen ${ }^{3}$ ).

In dem letzten Regierungsjahre des Abtes Wimar erliess der Erzbischöfliche Stuhl zu Köln für den Bereich des gesamten Steinfelder Pfarrbezirks eine Verordnung bezüglich der Kirchweilhfeste, welche bisher ron der Kirche zu Steinfeld und den benachbarten Kapellen dreimal im Jahre gefeiert wurden. Da aber an diesen Festtagen bei dem gewaltigen Zusammenströmen des Volkes aus allen Gegenden oft blutige Schlägereien stattfanden, welche für das Kloster grosse Unzuträglichkeiten im Gefolge hatten, be-

1) S. ebenda S. 77. Fabricius a. a. O. S. 156. Becker, Blankenhein S. $441 \mathrm{ff}$.

2) S. Frind a. a. O. II, S. $192 \mathrm{f}$. Leider ist es unmöglich, über die Zustände im Stifte Strahow während dieser Zeitperiode näheren Aufschluss zu erlangen, da das ganze Stiftsarchiv bei der Zerstörung des Stiftes durch die Hussiten im Jahre 1420 in Flammen aufging. (Gitig'e Mitteilung des Stiftsbibliothekars Cyrill Straka.)

3) S. die Originalurkunde im Staatsarchiv zu Düsseldorf. Keussen, Das Kloster Meer S. 76 f. Die Mitwirkung des Abtes Wimar bei $A b$ schliessung von Kauf-und Pachtvertràgen zugunsten des Klosters Meer und Dünwald s. Lacomblet a. a. O. II, S. 575 Nr. 975. Zeitscbr. des Berg. Geschichtsvereins 20, S. 79. Ennen, Quellen 3. Bd., S. 381 Nr. 397, 
fall der Erzbischof Wichbold dem Abte und dem Konvent kraft des Gehorsams und unter Strafe der Exkommunikation am 14. Mai 1298 , dass in Zukunft für alle Pfarreingesessenen zusammen nur eine Feier am Tage vor Christi Himmelfabrt obne Lärm und Ausschweifung stattfinden solle ${ }^{1}$.

ob der Abt Wimar diese Verordnung noch erlebte, bleibt ungewiss, da sein Name in der erzbischöflichen Urkunde nicht genannt ist. Ebenso zweifelhaft ist es, ob die einstweilige Regelung der Streitsache wegen des dem Kloster Steinfeld gebörigen Hofes Königsfeld ${ }^{2}$ ) noch in seine Regierungszeit fällt, da die Urkunde, welche über sie Aufschluss gibt, undatiert ist. Dagegen stelt fest, dass der Steinfelder Abt von dem Propst Conrad von Münstereifel and Pfarrer in Weyer ${ }^{3}$ ) (im Kreise Schleiden) die Zusicherung erhielt, er werde in dem schwebenden Streite, solange er lebe, das Kloster Steinfeld nicht belästigen oder gerichtlich belangen und nicht Bürgschaft fordern, wenn es wegen dieser Sache verklagt würde. Zugleich versprach er, für die Wiederherstellung des Friedens und der Eintracht ernstlich arbeiten und den Parteien beistelen zu wollen, falls zwischen dem Kloster Steinfeld and seiner Pfarre Weyer von nenem Streit oder Klage entstehen sollte; wenn aber beide Parteien von einem gerichtlichen Vorgeben nirht ablassen wollten, werde er sie bei jedem zuständigen Richter ungestört ibr Recht suchen lassen ${ }^{4}$ ).

\section{Die Abtei Steinfeld um die Wende des 13. Jahrhunderts.}

11. Abt Adolf von Dollendorf (1298-1304).

Der letzte Abt, welcher im Ausgange des 13. Jahrhunderts die Leitung des Steinfelder Klosters übernahm, war Adolf aus

1) S. Lacomblet a. a. O. II, S. $580 \mathrm{Nr} .986$.

2) S. oben S. 92 .

3) S. Fabricius a. a. O. S. 173.

4) S. Annalen 23, S. 190 f. Mitt. a. d. Stadtarchiv 4, S. 37. Vgl. die inhaltlich gleichlautende Originalurkunde $\mathrm{Nr}$. 32 vom 2?. Februar 1299 im Staatsarchiv zu Düsseldorf. Die Steinfelder Kirche feierte das Gedächtnis des Abtes Wimar gemäss ihrem nur fragrmentarisch erhaltenen Nekrolog am 9. April, 30. April und 19. November, die Abtei Rommersdorf am 27. März. S. Boos, Eufalia 3. Heft, S. 46. 48. 50. Wegeler a. a. O. S. 91 . 
dem edlen Geschlecht der Herren von Dollendorf im Kreise Schleiden, ein Sohn Gerlachs I. und seiner Gemahlin Mechtilde von Limburg ${ }^{1}$ ). Nachdem er in den geistlichen Stand eingetreten und Kanonikus an St. Gereon in Köln geworden war, nahm er das Kleid des heiligen Norbert und wurde Schatzmeister in Stein. feld, sodann nach erfolgter Präsentation seitens der Äbtissin Mathide von Frauenkron am 18. November 1271 Pfarrer in Alendorf, später Prior in Meer, 1295 Abt in Knechtsteden und 1298 Abt in Steinfeld ${ }^{2}$ ).

Für die Abtei erwarb er am 18. März 1299 von dem Grafen Gerhard VII. von Jülich, Herrn zu Kaster und Grevenbroich ${ }^{3}$ ), den Neubrucbszehnten in den Ortschaften Rövenich im Kreise Euskirchen und Disternicb im Kreise Düren gegen eine jährliche Erbrente von 3 Maltern Weizen; die von dem Klosterhofe in Bessenich im Kreise Euskirchen zu entrichten war $\left.{ }^{4}\right)$. Von der Ritterschaft, den Schöffen und Pfarrgenossen von Ober- und Niederzier ${ }^{5}$ ) erhielt er am 8. Januar 1302 als Ersatz dafür, dass er den sogenannten Mönchbusch der Gemeinde Zier einverleibte, zwei Rittergewalten, die eine für den Hof in Hochkirchen, die andere für den Hof in Oberbolbeim ${ }^{6}$ ). Als das Kloster Hamborn mit dem Kloster Steinfeld wegen des Patronatsrechts über die Pfarre zu Hochkirchen, welches abwechselnd den beiden Klöstern zustand ${ }^{7}$ ), in Streit geriet, kam der Abt Adolf mit dem Ham.

1) Seit dem Tode ihres Gernahls im Jahre 1260 hatte Mechtilde dem Kloster Steinfeld Jahr für Jahr sämtlichen Weizen geschenkt, welcher zur Bereitung der Hostien erforderlich war. S. Schannat-Bärsch a. a. O. 1. Bd. 1. Abt, S. 454. Ungefähr um dieselbe Zeit, als der Edelherr Adolf v. Dollendorf dem Kloster Steinfeld als Abt vorstand waren mehrere Mitglieder aus Kölner Patrizierfamilien Chorherren in Steinfeld, Werner und Cuno aus dem Geschlechte Birclin vom Horn und Heinrich aus dem Geschlechte Schönwetter. S. Mitt. a. d. Stadtarchiv 25 , S. $367 ; 26$, S. 145.

2) S. die series praep. et abb. Steinf. Kenssen a. a. O. S. 52. Becker, Blankenheim S. $133 \mathrm{ff}$.

3) S. Zeitschr. des Aachener Geschichtsvereins 4, S. 283 ; 11, S. 142.

4) S. die Originalurkunde im Stadtarchiv \&u Köln. Mitt. a. d. Stadtarchiv 4, S. 39.

5) S. Fabricius a. a. O. S. $79 \mathrm{f}$.

6) S. Lacomblet a. a. O. III, S. 10 Nr. 16. Mitt. a. d. Stadtarchiv 4, S. 45. Zeitschr, des Aachener Geschichtsrereins 6, S. $134 \mathrm{f}$.

7) S. oben S. 65. Das Kloster Hamborn hatte die andere Hälfte des 
borner tht Conrad darin überein, die Entscheidung dem Propste (Wermundus oder Johannes) ${ }^{1}$ ) von Kappenberg, dem Prior Jakob von Heer ${ }^{2}$, und dem Provisor Laurentius von Knechtsteden als Schiedsrichtern zu ibertragen. Diese erkannten am 30. Juli 1299, dass das Kloster Hamborn jedesmal, wenn es an der Reihe sei, den (')orherrn der Steinfelder Kirche, welchen der Steinfelder Konvent ihm vorgeschlagen habe, unverzüglich dem Archidiakon präsentieren nnd die Gerichtskosten mit tragen müsse, falls bei Gelegen. heit einer solchen Präsentation das Steinfelder Kloster in einen Prozess verwickelt werde. Andererseits erhielt dieses Kloster die Auflage, dem Kloster Hamborn jährlich am Feste des heiligen Nartinus 18 Malter Weizen zu liefern als Ersatz für den Ausfall an Einkünften, welcher dem Kloster dadurch erwuchs, dass der Pastor von Hochkirchen niemals aus seinen Reihen, sondern immer als den Steinfelder Chorherren genommen wurde ${ }^{3}$ ).

Nach sechsjähriger Regierung legte Adolf sein Amt in Steinfeld freiwillig nieder, wurde wieder Prior in Meer, 1315 Prior in Reichenstein und 1319 nochmals Abt in Knechtsteden. Nachdem er dem letzteren Kloster zwei Jahre und fünf Monate vorgestanden hatte, entsagte er auch diesem Amte und lebte bis zu seinem Tode, dessen Zeit und Ort unbekannt sind, ron den Rentenbezügen, welche er sich durch seine Stiftung vom Jahre 12904) gesichert hatte ${ }^{5}$.

Patronatsrechts um das Jahr 1250 von dem Grafen Heinrich von Wickrath und seiner Gemahlin Sophie empfangen. S. Hugo, Annales II, col. $869 \mathrm{sq}$.

1) Da Wermundus im Laufe des Jahres 1299 sein Amt niederlegte, der Tag seines Rücktritts aber unbekannt ist, lässt sich nicht ermitteln, ob er oder sein Nachfolyer Johannes am 30. Juli 1299 das Schiedsrichterant ausübte. S. Hug*o, Anuales I, col. 469.

2) Er war früher Sakristan in Steinfeld gewesen. S. Keussen a. a. O.S. 52. In Verbindung mit diesem Prior Jakob, seinem Antsnachfolger in Meer, gab der Abt Adolf dem dortigen Stifte am 24. Juli 1299 seine Genehmigung zur Veräusserung einer Rente von 6 Mark. S. Lacomblet a. a. O. II, S. $605 \mathrm{Nr} .1030$.

3) S. Anualen 23, S. 189 f. Mitt. a. d. Stadtarchiv 4, S. 39 f.

4) S. oben S. 114.

5) S. die ser. praep. et abb. Steinf. Hugo, Annales II, col. 856 sq. 